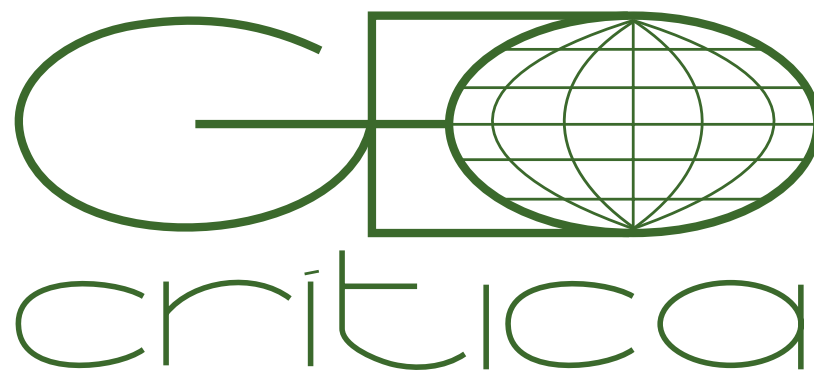

\section{Scripta Nova}

Revista Electrónica de Geografía y Ciencias Sociales Universitat de Barcelona

1 de agosto de 2017

\title{
EL ESPACIO PÚBLICO EN PERIFERIAS DESFAVORECIDAS: AÑAZA Y SANTA CLARA PARADIGMAS DE VULNERABILIDAD SOCIOESPACIAL EN SANTA CRUZ DE TENERIFE (CANARIAS-ESPAÑA)
}

\author{
Juan Samuel García-Hernández \\ Universidad de la Laguna \\ jgarciah@ull.edu.es
}

Recibido: 26/07/2016; Aceptado: 21/12/2016

Este trabajo forma parte del Proyecto de Investigación "Crisis y vulnerabilidad en ciudades insulares españolas. Transformaciones en los espacios de reproducción social" (CSO2015-68738-P) financiado por el Plan Nacional de I+D+i del Ministerio de Economía y Competitividad (AEI/ FEDER, UE). Cofinanciado por la Agencia Canaria de Investigación, Innovación y Sociedad de la Información de la Consejería de Economía, Industria, Comercio y Conocimiento y por el Fondo Social Europeo (FSE) Programa Operativo Integrado de Canarias 2014-2020, Eje 3 Tema Prioritario 74 (85\%).

\section{El espacio público en periferias desfavorecidas: Añaza y Santa Clara paradigmas de vulnerabilidad socioespacial en Santa Cruz de Tenerife (Resumen)}

Se examina el significado que adquiere el espacio público en la vida cotidiana de los residentes en dos barrios de la periferia urbana de Santa Cruz de Tenerife. El objetivo es determinar, mediante el análisis de caso, la incidencia de estos lugares de relación en la vulnerabilidad socioespacial de los barrios más desfavorecidos. Con esa finalidad se estudian, mediante técnicas cualitativas, las pautas de frecuentación, así como las actividades que los vecinos llevan a cabo en los espacios públicos seleccionados y los sentimientos de pertenencia que hacia ellos desarrollan.

Palabras clave: Espacio público, prácticas sociales, políticas urbanas neoliberales, barrios desfavorecidos, Santa Cruz de Tenerife

\section{Public space in disadvantaged peripheries: Añaza and Santa Clara para-} digms of sociospatial vulnerability in Santa Cruz de Tenerife (Abstract) The meaning of public space in the daily life of residents in two neighborhoods of the urban periphery in Santa Cruz de Tenerife is examined. The objective is to determine, through case study, the incidence of these places in sociospatial vulnerability of the most disadvantaged neighborhoods. For this purpose are studied through qualitative techniques, patterns of attendance, activities and feelings of belonging that residents have towards selected public spaces.

Keywords: space, social practices, neoliberal urban policies, disadvantages neighborhoods, Santa Cruz of Tenerife. 
Una parte sustancial de las investigaciones de las últimas décadas sobre las ciudades $^{1}$ ha puesto de relieve que el espacio público es un componente esencial de la calidad de vida urbana ${ }^{2}$. Su importancia queda constatada atendiendo a cualquiera de sus dimensiones - urbanística, jurídica, económica, cultural, simbólica...-, si bien en este trabajo se analiza su papel como lugar para la sociabilidad, esto es, como ámbito de uso público y acceso libre donde una gran diversidad de usuarios puede acudir para desarrollar una amplia variedad de actividades 3 . Se focaliza el interés en plazas y parques, pues del conjunto de espacios que desde una aproximación jurídica se consideran de uso y dominio público, son estos en los que de modo habitual se desarrolla la vida urbana, el encuentro y la relación social, lugares donde las personas forjan sus identidades y establecen códigos de conducta 4 . Esta concepción supone incorporar a su dimensión física, una dimensión social que es su consideración como lugar, noción que entronca con la idea de que la producción de la ciudad y, en consecuencia, la de estos espacios, debe entenderse en un sentido amplio "producción de obras y producción de relaciones sociales"5.

En entornos urbanos desfavorecidos, la provisión de espacios públicos de calidad es una de las acciones que la administración puede emprender para favorecer la equidad, pues la posibilidad de hablar de un auténtico proyecto de ciudad se atenúa si todos sus residentes no cuentan con lugares públicos adecuados que hagan posible el ocio, el encuentro y la expresión colectiva. En esta línea, la presente aportación es deudora de los planteamientos de H. Lefebvre que remiten a la idea de que todos los ciudadanos tienen derecho a la ciudad, a su movilidad en ella y a sentirse identificados con el espacio en el que desarrollan su vida cotidiana. Desde esta perspectiva, el significado social que adquieren para los residentes los espacios públicos es indudable, pues su provisión acorde a las demandas ciudadanas, además de ser una de las vías para mejorar la calidad de vida de la población ${ }^{6}$, puede entenderse como la exigencia ética de poner a la ciudad al servicio de sus habitantes ${ }^{7}$ y así, contribuir a su bienestar, en particular en ámbitos con procesos de vulnerabilidad y riesgo de exclusión social ${ }^{8}$. Frente a esta concepción de ciudad y de las funciones a desempeñar por los gobiernos locales, se advierte que tanto las propuestas como las intervenciones que en las últimas décadas aplican las administraciones apuntan en una dirección distinta. La preocupación por el posicionamiento de su ciudad en el mercado global motiva la concentración de las inversiones y la atención hacia la mejora de

1 Borja y Muxi, 2001, Mitchell, 2003, García-Ramón, Ortiz y Prats, 2014.

2 Se entiende la calidad de vida como un constructo multidimensional que remite a todas las esferas de la vida cotidiana de los individuos y que incorpora, además de los indicadores relacionados con la capacidad de una persona o grupo social para satisfacer un determinado nivel de bienestar, parámetros subjetivos y no cuantificables que recogen la satisfacción del individuo con su vida.

3 García-Ramón, Ortiz y Prats, 2004.

4 Vaiou y Lykogianni, 2006, Janoschka, 2011, Borja, 2012.

5 Lefebvre, 1969, p.65.

6 Caquimbo, 2008.

7 Lefebvre, 1968.

8 Harvey, 2007, Marcuse, 2010. 
la imagen y la potenciación de ciertas funciones en determinados espacios públicos que, por su ubicación, son importantes para el marketing urbano y la estrategia de competitividad 9 . Al mismo tiempo, esta fijación es paralela a la falta de atención que se otorga al espacio público en las periferias desfavorecidas, al comprobarse en estudios previos que buena parte de las deficiencias heredadas se mantienen o refuerzan por la falta de atención y reducido mantenimiento ${ }^{10}$.

En virtud de lo expuesto, esta investigación se propone explorar si en los procesos de vulnerabilidad y exclusión de los barrios desfavorecidos analizados intervienen, junto a las variables sociales y económicas, la dimensión físico-espacial y, en concreto, la situación de los espacios públicos de relación vecinal. Con ese objetivo se examinan las pautas de uso y frecuentación, así como los factores que condicionan la presencia de colectivos, prácticas diversas y el desarrollo de sentimientos de pertenencia hacia los espacios públicos de estudio. Se parte de la premisa de que un entorno o ambiente inadecuado puede reforzar o incluso propiciar procesos de vulnerabilidad y exclusión socioespacial ${ }^{11} \mathrm{y}$, a partir de ahí, con el análisis particular en las plazas y parques más representativos de los barrios seleccionados, se pretende mostrar que la cantidad y calidad de los espacios públicos es un factor más de su vulnerabilidad y no solo su expresión o consecuencia. Tal es así, que se plantea que el deficitario estado que presentan estos lugares de relación se convierte en una de las manifestaciones más evidentes de la diferenciación ciudadana y se halla entre las principales razones de su limitado uso vecinal. En estos ámbitos, las condiciones sociales, pero también las espaciales requieren especial atención para evitar contextos más graves de vulnerabilidad pues, tal y como se ha señalado el menosprecio al espacio público supondría dejar de lado a los residentes y contribuir al reforzamiento de los procesos de segregación social y espacial ${ }^{12}$.

El trabajo se organiza en cuatro apartados. En el primero se reflexiona sobre el papel protagonista del espacio público en los procesos de desigualdad socioespacial y vulnerabilidad urbana. A continuación, se exponen los procedimientos metodológicos empleados. En tercer lugar, se describe el contexto espacial -la ciudad de Santa Cruz de Tenerife y sus áreas vulnerables-, se caracterizan los dos barrios seleccionados - Santa Clara y Añaza-, así como los dos espacios públicos que se estudian en profundidad en cada barrio. Por último, se plantean los resultados alcanzados, con especial atención a la frecuentación, prácticas sociales y sentimientos de pertenencia e identificación ciudadana.

\section{Desigualdad y vulnerabilidad socioespacial: El espacio público, retra- to de desequilibrios intraurbanos}

La desigualdad socioespacial, la vulnerabilidad urbana y la consiguiente existencia de bolsas de pobreza y exclusión son cuestiones de gran importancia social, política

9 Brenner y Theodore, 2002, Mitchell, 2003, Harvey, 2007, Armas, 2016.

10 Madanipour, 2010, Torres, 2005.

11 Torres, 2005, Savage, Warde y Ward, 2003.

12 Borja y Muxi, 2001. 
y de interés intelectual ${ }^{13}$. La ubicación diferencial de las personas en el territorio en relación con su capacidad económica y/o condición social genera una estructura socioespacial segregada que parece agravarse en las últimas décadas en correspondencia con el proceso de crecimiento de las ciudades ${ }^{14}$ y aún más, con la crisis iniciada en 2008 y las políticas neoliberales de austeridad puestas en marcha para contrarrestar sus efectos ${ }^{15}$. Diversos autores ${ }^{16}$ apuntan que tales políticas no parecen haber contribuido a resolver o disminuir el problema de la segregación, sino que más bien lo agravan, produciéndose un incremento en la desigualdad de ingresos, en las dificultades de acceso a la vivienda y un aumento del número de sujetos en situación de vulnerabilidad. Para Harvey ${ }^{17}$ “los cambios económicos, globalizadores e informacionales tienen también una traducción espacial, construyendo "zonas de integración" y "zonas de exclusión" social y territorial". Borja y Castells (1998), por su parte, señalan que un alto riesgo de la globalización es que se haga para una élite: "...se vende una parte de la ciudad y se abandona el resto"18. Se estaría generando una ciudad cuarteada, con desigualdades socioespaciales e identidades propias para cada zona, cuyos sectores desfavorecidos son separados del resto de la ciudad por barreras físicas y psicológicas ${ }^{19}$.

En estos procesos de inclusión/vulnerabilidad/exclusión de las distintas partes del tejido urbano se ha otorgado a la variable renta un papel central. Sin embargo, su capacidad explicativa no es absoluta pues, a los frecuentes análisis de la desigualdad en términos económicos, recientemente se han añadido otros indicadores que amplían la dimensión del fenómeno y dan idea de su complejidad al incluir, entre otros factores o componentes, el medio ambiente, el bienestar social o la accesibilidad ${ }^{20}$. Desde esta perspectiva, se comprueba que un barrio no se degrada solo por la débil capacidad adquisitiva de sus habitantes, sino que deben concurrir otros factores que actúen de forma simultánea para transformar la mera segregación espacial por renta, en vulnerabilidad y exclusión social ${ }^{21}$. Se debe tener presente que la vulnerabilidad social remite a la combinación de "múltiples dimensiones de desventaja en que toda esperanza de ascenso social, de superación de la condición de pobreza o próxima a ella, se ve como extremadamente difícil de alcanzar y, en cambio, conlleva la percepción de inseguridad ante la posibilidad de un empeoramiento de las actuales condiciones de vida"22. Se puede afirmar, por tanto, que la vulnerabilidad es una noción multidimensional que afecta a distintos planos del bienestar de diversas formas y con diferentes intensidades. El Atlas de la Vulnerabilidad Urbana de Espa-

13 Bühler, Kaspar y Ostermann. 2010, Torres y García, 2011.

14 Vilagrasa, 2000, Sabatini, 2003.

15 Vives-Miró y Rullán, 2014, Méndez, Abad y Echaves, 2015.

16 Harvey, 1977, Marcuse, 1993, Alguacil, 2006.

17 Citado en Torres 2005, p.25.

18 citado por Segovia y Jordán, 2005, p.8.

19 Marcuse, 1993.

20 Hills, Le Grand y Piachaud, 2002, Alguacil, Camacho y Hernández-Aja, 2014.

21 Bruquetas, Moreno y Walliser, 2005.

22 Alguacil, 2006:151. 
ña de 2011 tiene presente esa consideración y añade a la dimensión económica ${ }^{23}$ otros indicadores de vulnerabilidad - residencial, sociodemográfica y subjetiva-24 cuya importancia no se debe obviar, pues introducen aspectos relevantes para comprender la desventaja social de los residentes en determinadas áreas urbanas.

Este carácter multidimensional de la vulnerabilidad ha sido uno de los focos de atención de la geografía crítica que incide en la relación entre la forma espacial y los procesos sociales que se dan en la urbe. Resulta evidente que la realidad territorial de las diferentes áreas de la ciudad varía en función de la realidad social existente, lo que remite al planteamiento de que "toda teoría general de la ciudad ha de relacionar, de algún modo, los procesos sociales con la forma espacial que la ciudad asume"25.

Con independencia de la escala que se maneje, la reducción de las desigualdades espaciales es factible frenando la tendencia a la concentración espacial de las inversiones, lo que cristaliza en el ámbito urbano, por ejemplo, en la confluencia de grandes actuaciones privadas y públicas en ciertas áreas céntricas, dirigidas a la renovación de la imagen en un marco de competitividad urbana cada vez más acusado $^{26}$. En un contexto de intensificación de la globalización económica y hegemonía del pensamiento neoliberal, las políticas urbanas sufren presiones por parte de intereses que abogan por la puesta en marcha de estrategias orientadas a reforzar una determinada actividad ${ }^{27}$. Se potencia una perspectiva en la que la ciudad en su conjunto carece de valor y solo una parte de ella resulta rentable para los intereses particulares, lo que tiene como resultado un incremento de la polarización social $^{28}$. Tal es así, que se evidencia que las políticas urbanas neoliberales dejan en un segundo plano compromisos sociales de primer orden como el empleo o la vivienda para centrar sus esfuerzos en la obtención de beneficios, lo que conduce a un incremento de la vulnerabilidad de determinados grupos sociales ${ }^{29}$. En este sentido, conviene tener presente que la atención prestada por parte de las administraciones públicas a los sectores urbanos más emblemáticos, se produce de forma simultánea a la dejación de otras áreas en las que residen los grupos desfavorecidos, que lo son no solo porque posean unos niveles de renta inferiores, sino también por el estado en el que se encuentran sus viviendas, la accesibilidad que tienen sus residentes a determinados equipamientos y servicios, o por la dotación y estado

23 Ha sido la más empleada debido a su propia importancia y al hecho de que se dispone de más variables indirectas para su medición como los niveles de desempleo, de ocupación eventual o de población sin estudios.

24 Se contempla una vulnerabilidad residencial con indicadores como la antigüedad y superficie de la vivienda, personas en viviendas sin servicio o aseo y estado de conservación; la vulnerabilidad sociodemográfica incluye, entre otros, índice de extranjería, nivel de envejecimiento y hogares monoparentales, y la subjetiva hace referencia a las percepciones de los residentes sobre su espacio cotidiano de vida: ruidos, contaminación, escasez de zonas verdes, malas comunicaciones, delincuencia.

25 Harvey, 1977, p.16.

26 Brenner y Theodore, 2002, Talesnik y Gutiérrez, 2002, Blanco y Subirats, 2012.

27 Díaz Orueta y Lourés Seaone, 2014.

28 Hackworth, 2013 y Hodkinson, 2013.

29 Janoschka, 2011. 
de los espacios públicos en sus ámbitos de residencia. En definitiva, la brecha entre unas áreas urbanas y otras, si bien tiene un origen económico, se agranda y se extiende hacia las condiciones materiales de los espacios de reproducción social: viviendas, equipamientos y espacios públicos. Frente a esta situación, el reequilibrio entre áreas urbanas desiguales debería constituir un objetivo prioritario, mediante la recualificación urbana y social de los barrios peor posicionados en base a unas políticas públicas más equitativas que las actuales ${ }^{30}$. Es por ello que adquiere relevancia el análisis de los escenarios espaciales en los que se desarrolla la vida cotidiana, pues estos pueden actuar como ingredientes esenciales en el bienestar de los ciudadanos, si se convierten en espacios donde el intercambio de ideas suplante al valor de cambio, al comercio y al beneficio ${ }^{31}$. La mejora de la calidad en ámbitos vulnerables de estos lugares de simultaneidad y encuentro es una de las vías que puede y debe utilizar la administración para avanzar hacia una mayor cohesión territorial y social, mientras, en sentido inverso, su desconsideración puede acentuar los procesos de vulnerabilidad y exclusión preexistentes ${ }^{32}$.

Es aquí donde se plantea la importancia particular de la dotación y el estado de los espacios públicos de relación vecinal. El espacio público es un espacio físico, simbólico y político; es, a un tiempo el espacio principal del urbanismo, de la cultura urbana y de la ciudadanía, por lo que su calidad, las funciones que pueda cumplir y su accesibilidad definirán en buena medida el progreso colectivo ${ }^{33}$. En áreas desfavorecidas, es habitual que tales ámbitos sean escasos en cantidad y calidad y pobres en producción de sentido ${ }^{34}$, cuando su especial interés en periferias sociales y urbanas se fundamenta en su importancia para combatir situaciones complicadas. La existencia de lugares que propicien la relación social y el encuentro provee de cierta estabilidad y confianza frente al contexto de inseguridad que padecen muchas veces los residentes en tales áreas ${ }^{35}$. De este modo, se considera que aunque la mayor calidad del espacio público no contribuye de manera directa a resolver los problemas de índole social, sí que puede ayudar a mejorar las condiciones de vida de la población ${ }^{36} y$, por tanto, su mejora resulta esencial. En este sentido, las políticas públicas juegan un papel principal, especialmente de ámbito local, que deben poseer capacidad de generar y custodiar un espacio público que cumpla una función integradora, facilite el acceso y la participación de todos y pueda ser un importante mecanismo de integración social ${ }^{37}$. La disponibilidad de espacios abiertos, accesibles y de calidad para realizar actividades colectivas favorece la convivencia ciudadana y, a través de sus atributos intangibles e inmateriales, puede fortalecer el sentimiento de pertenencia a una comunidad. En definitiva, el análisis que se efectúa tratará de

30 Percy-Smith, 2000.

31 Lefebvre, 1969.

32 Saraví, 2004, Subirats, Alfama y Obradors, 2005, Caquimbo, 2008.

33 Borja y Muxi, 2001.

34 Saraví, 2004, Borja, 2012.

35 Capdeville, Ceconato y Mandrini, 2013.

36 Caquimbo, 2008.

37 Perahia, 2007. 
mostrar si los espacios públicos de los barrios desfavorecidos de la ciudad de estudio contribuyen, en su estado actual, a reforzar el vínculo social y facilitar el encuentro y la convivencia o si, por el contrario, estarían dificultándolos como ocurre con frecuencia en áreas pobres con procesos de vulnerabilidad y exclusión social ${ }^{38}$. Su estudio constituye, por tanto, una muestra del ejercicio analítico que implica conocer e interpretar las relaciones entre las condiciones espaciales en que los residentes desenvuelven su existencia diaria y su ambiente social ${ }^{39}$.

En el marco de los estudios recientes sobre los espacios públicos de relación vecinal se inscriben aquellos que, desde perspectivas diversas, analizan el uso, las prácticas sociales y los significados que le otorgan los residentes en el desarrollo de su vida diaria. Las investigaciones desde este enfoque plantean que la ciudadanía no se debe estudiar como una categoría homogénea, al evidenciarse desigualdades entre grupos identitarios en la consecución de su derecho a la ciudad y, en consecuencia a su espacio público. En este sentido, se considera la existencia de diferencias entre las prácticas y experiencias cotidianas de hombres y mujeres y se aprecia la exclusión femenina en determinados espacios dominados y apropiados por la identidad masculina ${ }^{40}$.

Asimismo, otros trabajos han incorporado la edad, el contexto social de procedencia y otras dimensiones individuales y culturales que también introducen diferencias en las prácticas y comportamientos cotidianos ${ }^{41}$. En este estudio, como se verá más adelante, se reconocen ciertas pautas de ocupación del espacio público en función de los rasgos identitarios. De igual modo, destacan las aportaciones que se ocupan de analizar los sentimientos de pertenencia hacia los espacios en los que los residentes desarrollan su vida ${ }^{42}$, lo que tiene su origen en los planteamientos que indican que son los lazos emotivos y simbólicos los que convierten al espacio en algo más que un contenedor físico, al transformarlo en lugares vividos cargados de sentido y de historia ${ }^{43}$. Los espacios públicos de áreas urbanas desfavorecidas presentan generalmente carencias en relación con las dos líneas aquí planteadas. En ellos se manifiestan limitaciones de uso para determinados grupos que pueden sentirse excluidos al apropiarse de ellos otros colectivos de modo excluyente o porque las condiciones físicas del espacio dificultan el acceso y la estancia ${ }^{44}$. Asimismo, su carácter indiferenciado, la nula implicación ciudadana en su diseño y gestión y la ausencia de valor simbólico influyen en la falta de apego y sentimientos de pertenencia hacia estos ámbitos de uso colectivo ${ }^{45}$. En definitiva, los espacios públicos son ingredientes claves para un adecuado funcionamiento del conjunto social, por su importancia en el desarrollo de la vida colectiva y, en último término, en la mejora de la calidad

38 Madanipour, 2010.

39 Barry, 2002.

40 Fenster, 2005, Vaiou y Lykogianni, 2006, García-Ramón, Ortiz y Prats, 2014.

41 Valentine, 2007, Mäkinen y Tyrväinen, 2008, Rodó-de-Zárate, 2011, Díaz et al., 2015.

42 Ortiz, 2006, García et al. 2014.

43 Tuan, 1977, Ley y Samuels, 1978. .

44 Mitchell, 2003, Saraví, 2004, Díaz-Cortés, 2009.

45 Janoschka, 2011, Benach, 2015. 
de vida de la población. En aquellas áreas urbanas socialmente más vulnerables es habitual encontrar espacios de relación ciudadana escasos en cantidad, de ínfima calidad y pobres en producción de sentido ${ }^{46}$, lo que estaría reforzando los procesos de vulnerabilidad y exclusión social y espacial en la ciudad contemporánea.

\section{Metodología aplicada}

La metodología empleada integra el análisis documental y el trabajo de campo. En el primer caso, la consulta de informes socioeconómicos recientes ${ }^{47}$ permite determinar el alcance de la desigualdad intraurbana y de las situaciones de vulnerabilidad social en Santa Cruz de Tenerife, al tiempo que facilita la caracterización de las áreas específicas de estudio. El trabajo de campo ha consistido, por un lado, en una observación sistemática no participante en los espacios públicos seleccionados ${ }^{48} \mathrm{y}$, por otro, en la realización de entrevistas semiestructuradas.

La primera técnica se aplica con el propósito de identificar las características básicas de edad y género de los usuarios, los momentos en que se produce su estancia y las actividades que desarrollan, por medio de un procedimiento similar al empleado en otras investigaciones ${ }^{49}$. Se eligen distintos momentos de recogida de la información porque cada espacio tiene sus propios ritmos de uso, que resultan cambiantes en función del turno - mañana, tarde, noche-, del día de la semana o de la temporada y, por tanto, no existe un espacio público arquetípico sino espacios-tiempo de agregación diversos ${ }^{50}$. De igual modo, se busca identificar si en los espacios analizados o en algunos de sus sectores se producen usos exclusivos y/o excluyentes - procesos de apropiación-, pues resulta habitual que algunos grupos precisen hacer uso propio de espacios, al desarrollar prácticas relativamente incompatibles entre sí. Por otro, se realizan doce entrevistas semiestructuradas, repartidas en similar proporción entre residentes en los dos barrios estudiados y entre sujetos con rasgos identitarios diferenciados - género, edad, status social- para tratar de diversificar el perfil de los entrevistados y sus opiniones ${ }^{51}$. Para la selección de las personas participantes se recurre a combinar diferentes estrategias que permitan obtener una muestra lo más representativa posible.

En primer lugar, el contacto directo con personas a través del trabajo de campo en los lugares de encuentro, tratando de incorporar a sujetos con rasgos diferenciados; a continuación, la consulta del Registro Municipal de Entidades Ciudadanas de Santa Cruz de Tenerife y de las redes sociales 2.0 ha sido de interés para tantear

46 Borja, 2012.

47 Atlas de Vulnerabilidad Urbana de España de 2011, Sociedad de Desarrollo de Santa Cruz de Tenerife de 2013, Diagnóstico Social de Santa Cruz de Tenerife de 2014.

48 Se han realizado 32 observaciones, a razón de ocho observaciones por cada espacio público, en turnos de mañana y tarde y en días laborables y festivos. Se llevan a cabo en las cuatro estaciones del año y en condiciones ambientales aceptables, sin viento o lluvia que pueda dificultar la presencia de usuarios.

49 Low, 2000, Ortiz, 2004, Ostermann, 2009, Díaz et al., 2015.

50 Amin, 2006.

51 Sabaté, Perdomo y Afonso, 2008, Wehrahn y Dominic, 2014. 
a colectivos implicados en la vida del barrio y, por último, la estrategia conocida como "bola de nieve" que permite el acceso a nuevos informantes a partir de los ya entrevistados conseguidos a partir de los anteriores procedimientos. Todas las entrevistas fueron grabadas y transcritas literalmente, validadas por los entrevistados y, finalmente, codificadas mediante la selección de los términos y significados más relevantes ${ }^{52}$. Esta técnica ayuda a comprender el por qué del uso o no de los espacios analizados, de las actividades que se desarrollan en ellos, las razones de los comportamientos observados, los sentimientos de pertenencia, y la experiencia cotidiana de las personas en relación con estos espacios de encuentro y relación vecinal ${ }^{53}$.

En definitiva, proporcionan información sobre las prácticas sociales, esto es, sobre cómo los ciudadanos desarrollan sus habilidades sociales, las formas de utilizar y percibir los lugares donde las practican, y en los que, como usuarios, ejercen una apropiación espontánea ${ }^{54}$.

\section{Contexto espacial y estudios de caso}

En este punto se presentan, en primer lugar, los aspectos más relevantes de la vulnerabilidad urbana en la ciudad de estudio, atendiendo a la ubicación de los ámbitos desfavorecidos y a los indicadores socioeconómicos que le otorgan esta condición y, en segundo lugar, se justifica el especial interés para su estudio en detalle de los barrios y espacios públicos seleccionados.

\section{Rasgos y espacios de vulnerabilidad social y espacial en Santa Cruz de Tenerife}

Santa Cruz de Tenerife es una ciudad portuaria, con poco más de 200 mil habitantes, cuya función capitalina contribuyó a su crecimiento demográfico y superficial en las décadas centrales del pasado siglo XX. La magnitud y el ritmo de este proceso de crecimiento y la rapidez con que se ampliaba el espacio edificado, con protagonismo importante de la autoconstrucción, se hallan en el origen de la vulnerabilidad en que se encuentran hoy determinados ámbitos de la ciudad ${ }^{55}$. Aspectos vinculados al funcionamiento urbano son considerados claves para entender su conformación actual. Entre estos podemos citar procesos comunes a los experimentados por otras muchas ciudades, tales como la gentrificación de áreas centrales, prácticas planificadoras que no benefician a todos los ámbitos de la ciudad por igual, efectos segregadores del mercado inmobiliario, la imagen colectiva que se difunde acerca de un espacio social con procesos de sobrevaloración o estigmatización y la contraposición de espacios exclusivos frente a otros sometidos a procesos de marginación y vulnerabilidad ${ }^{56}$. Aunque a partir de los años ochenta del siglo pasado, las administraciones públicas tratan de resolver los problemas derivados del crecimiento desordenado de la ciudad, mejorando equipamientos y dotaciones de las áreas menos

52 Bühler, Kaspar y Ostermann. 2010.

53 Taylor y Bogdan, 1996.

54 Lefebvre, 1991.

55 García, Armas y Díaz, 2013.

56 García, 2003, Torres y García, 2011. 
favorecidas, lo cierto es que el número de barrios en los que se superan los índices de vulnerabilidad establecidos como referencia es todavía importante. Si en el año 2001 el Ministerio de Fomento estimaba que el 41,30\% de la población de la ciudad residía en áreas urbanas vulnerables ${ }^{57}$, es razonable pensar que con la crisis actual se ha profundizado la precariedad en estas áreas de vulnerabilidad estructural, como ha ocurrido en otros contextos geográficos ${ }^{58}$ y como apuntan los informes recientes de la situación socioeconómica de la ciudad ${ }^{59}$.

Las áreas vulnerables tienen un reparto espacial desigual en las dos grandes unidades residenciales que se pueden diferenciar en Santa Cruz de Tenerife: la ciudad consolidada y la periferia suroeste ${ }^{60}$. En la ciudad consolidada se inscribe la primera periferia de barrios obreros que se desarrolla a partir de las décadas centrales del pasado siglo. En ella se sitúan nueve de las doce Áreas Estadísticas Vulnerables identificadas en 2011 , de acuerdo con los datos del censo de población y viviendas de $2001^{61}$. Se trata de espacios edificados en su mayor parte entre las décadas de 1950 y 1960, para grupos sociales de bajo nivel de renta por iniciativa pública, privada o levantados por la autoconstrucción de los vecinos ${ }^{62}$. En ellos se ha ido produciendo un envejecimiento de su población y viviendas, pero su característica más preocupante es la existencia de elevadas tasas de paro $^{63}$. Por su parte, en la periferia

57 El Atlas de la Vulnerabilidad Urbana de España de 2011 entiende por Área Estadística Vulnerable (AEV) la agrupación de secciones censales colindantes de cierta homogeneidad urbanística, en las que al menos uno de los tres indicadores básicos de vulnerabilidad urbana (vivienda, paro y estudios) supere el valor nacional de referencia. El objeto es establecer una delimitación urbanística que se corresponda con una realidad física y morfológica a través del trabajo de campo y de la información aportada por el técnico municipal.

58 Laparra, 2010, Fujita, 2013, Gómez y Alvarez, 2013.

59 El VII Informe sobre la exclusión y el desarrollo social en Canarias elaborado para Cáritas por la fundación Fomento de Estudios Sociales y Sociología Aplicada (Foessa) indica que a raíz de la crisis iniciada en 2008 las desigualdades, pobreza y el riesgo de caer en situaciones de exclusión social se ha incrementado de modo importante en España y Canarias, afectando en 2013 a un 35,5\% de la población del archipiélago. De igual modo, los informes consultados sobre el particular para la ciudad de Santa Cruz de Tenerife - Plan Estratégico Municipal de Servicios Sociales 2014-2018, Diagnostico Social del Instituto Municipal de Atención Social de 2014, Datos de la Sociedad de Desarrollo de $2013 . .$. - evidencian un empeoramiento de la situación económica y social en todos los distritos y, de modo especial, en aquellos que partían de situaciones previas de vulnerabilidad.

60 Se aplica la zonificación de la ciudad empleada por Díaz et, al. (2002), que distingue, por un lado, la ciudad consolidada - incluye la ciudad tradicional, su ensanche y los barrios obreros surgidos a partir de la expansión urbana de mediados del siglo XX-y, por otro, la periferia suroeste que, localizada en esa posición, comprende el espacio anexionado $(15 \mathrm{~km} 2)$ al municipio de Santa Cruz de Tenerife a mediados de la década de 1970. En su origen se trataba de una periferia en condiciones precarias de accesibilidad y carente de infraestructura y equipamientos públicos, que presenta, desde entonces, los mayores crecimientos tanto del número de habitantes, como de viviendas sociales. 61 La información corresponde al Atlas de la Vulnerabilidad Urbana de España y se incluyen Camino del Hierro-Somosierra, Chimisay, Duggi-Ramón y Cajal, Las Delicias-Nuevo Obrero, Los Gladiolos, Perú, Salud Alto, Salud Bajo, Santa Clara.

62 Ayuntamiento de Santa Cruz de Tenerife, 1983.

63 La Sociedad de Desarrollo de Santa Cruz de Tenerife, en un informe publicado en 2013, señala para los distritos de Ofra-Costa Sur y Salud-La Salle - en los que se insertan las áreas vulnerables de la primera periferia urbana- un paro registrado del $24,3 \%$ y el $20,8 \%$ respectivamente, muy superior a los niveles de otros distritos aventajados de la ciudad (13,6\% de Zona Centro). 
suroeste - situada al sur lindado con los municipios de San Cristóbal de La Laguna y El Rosario-, se localizan tres ${ }^{64}$ de los doce barrios vulnerables que existen en la ciudad (figura 1). Se trata de una zona formada por núcleos de diverso origen, que concentra los crecimientos demográficos de las últimas décadas y que incluye en la actualidad, junto a espacios que mantienen un importante componente rural, los nuevos desarrollos residenciales en los que adquiere gran protagonismo la vivienda de promoción pública ${ }^{65}$.

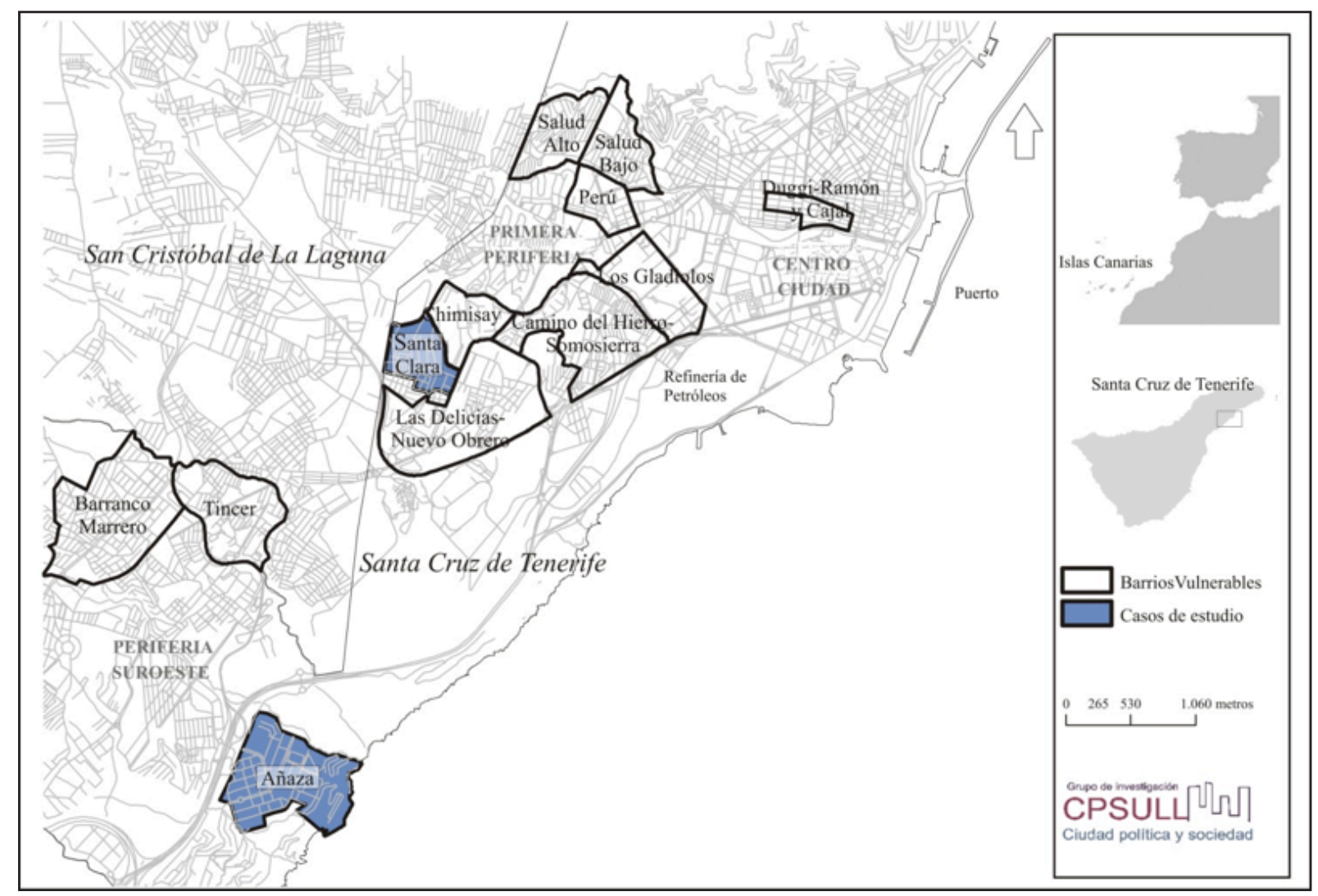

Figura 1: Localización de los barrios vulnerables de Santa Cruz de Tenerife.

Fuente: Ministerio de Fomento. Atlas de la vulnerabilidad urbana en España, 2011. Cartográfica de Canarias (Grafcan). Mapa topográfico, 2011. Elaboración A. Armas y J.S. García.

\section{La singularidad de los barrios desfavorecidos y de los espacios públicos seleccio- nados}

Los estudios de caso implican un cambio de la escala de análisis, desde el distrito o las áreas vulnerables hasta el barrio. Se trata en este último caso de un marco territorial en el que es posible estudiar el día a día de los ciudadanos y adecuado para la aplicación de la metodología cualitativa, por su reconocimiento colectivo y su potencial a la hora de extraer subjetividades, valor simbólico o sentimientos de pertenencia ${ }^{66}$. Se han seleccionado para su estudio en profundidad los espacios públicos más representativos de dos barrios: uno de la primera periferia obrera, Santa Clara,

64 Añaza, Barranco Marrero y Tíncer.

65 Díaz et al, 2002, García, Armas y Díaz, 2013.

66 Díaz-Cortés, 2009, Moulaert, Martinelli, Swyngedow y González 2010. 
y otro de la periferia suroeste, Añaza. Santa Clara, es un ejemplo del urbanismo de urgencia que se desarrolla en muchas ciudades en la década de 1960. Se trata de polígonos que se levantan con ínfima calidad de la edificación, en situación de aislamiento, con viviendas de superficie reducida y servicios mínimos en su interior. El nivel de deterioro que define el origen de estos suburbios oficiales planificados ${ }^{67}$, ha obligado con el tiempo a la reposición de sus inmuebles ${ }^{68}$. Con ser muy importante la corrección de estas carencias básicas, no se acompaña de mejoras en otros aspectos igualmente esenciales desde el punto de vista de la vulnerabilidad ${ }^{69}$. De este modo, el barrio de Santa Clara, con un volumen poblacional de 5.155 residentes registra, incluso con anterioridad a la crisis, unas condiciones sociales desfavorables, que para 2001 se evidencian en elevadas tasas de paro $(21,47 \%)$ y una proporción de población sin estudios y con viviendas en mal estado ( $23,38 \%$ y $9,44 \%$ respectivamente) superior a la media municipal ${ }^{70}$. Tras el estallido de la crisis económica en 2008, la situación social de Santa Clara experimenta un retroceso significativo, pues según el I Plan Municipal de Prevención Social y Desarrollo Comunitario, elaborado por el Instituto Municipal de Atención Social (IMAS) en 2014, este sector de la ciudad ocupa el primer lugar a escala municipal por la cifra de demandantes de ayuda, lo que se justifica, entre otros factores, por el hecho de que en torno al 50\% de los hogares perciben ingresos inferiores a 1.000 euros.

El barrio de Añaza, por su parte, se ubica en un sector de expansión periférica, alejado de la ciudad compacta, en el que se concentra la vivienda pública de finales del siglo XX y principios del actual. El barrio se empieza a edificar en la década de 1980 con viviendas de promoción pública ${ }^{71}$ a las que se añaden en la década de 1990, bloques de iniciativa privada. Resulta sintomático que, a finales del siglo XX se levanten en un contexto democrático, conjuntos residenciales como el de Añaza, que surge en entornos aislados y carentes de servicios y equipamientos básicos. Es decir, se trata de actuaciones que implican de nuevo la concentración de los grupos más desfavorecidos de la ciudad en su periferia más alejada y desconectada ${ }^{72}$. A pe-

67 García, 2005:271.

68 La reposición de Santa Clara formó parte del Convenio del Patronato de La Candelaria, un acuerdo suscrito en 1992 entre el Ministerio de Fomento, el Gobierno de Canarias, el Cabildo de Tenerife y el Ayuntamiento de Santa Cruz para la reposición de 1116 viviendas en Santa Clara y San Pío. La ejecución de este proyecto de 10.000 millones de pesetas por la empresa Viviendas Municipales se produjo a lo largo de una década y supuso la demolición y posterior reconstrucción de 816 viviendas en Santa Clara y 300 en San Pío (Pérez, 2000).

69 El Atlas de la Vulnerabilidad Urbana de España de 2011 apunta que del conjunto de barrios vulnerables de la ciudad de Santa Cruz, es Santa Clara el único que supera los tres índices de referencia para la determinación de áreas de vulnerabilidad urbana - vivienda, paro, estudios-.

70 Ministerio de Fomento, 2011.

71 El Plan Parcial de Añaza se desarrolla a iniciativa del Ayuntamiento de Santa Cruz de Tenerife que, a finales de la década de 1970, busca suelo para la construcción de viviendas sociales. Su aprobación en 1982 implica a diversas entidades: Instituto de Promoción Pública de la Vivienda (I.P.P.V.), Viviendas Sociales de Canarias (VISOCAN), Gestión Urbanística de Santa Cruz de Tenerife (GESTUR) y Caja de Ahorros de Santa Cruz de Tenerife, encomendando a GESTUR la gestión del planeamiento (Ayuntamiento de Santa Cruz de Tenerife, 1990)

72 García, Smith y Mejías, 2007. 
sar de que Añaza cuenta con una planificación previa, con usos zonificados y con reserva suficiente de suelo para equipamientos y espacios públicos, este barrio es una muestra significativa de la gestación de ámbitos vulnerables en aquellos años. A su difícil situación inicial contribuyen, entre otros rasgos, su lejanía respecto a la ciudad $(8 \mathrm{~km})$, su carencia de conexiones mediante transporte público, la proximidad de instalaciones industriales molestas, la dotación de vivienda social destinada al realojo de habitantes desplazados desde distintas zonas de infravivienda de la ciudad, su carácter de barrio exclusivamente dormitorio, la nula dotación de equipamientos, servicios básicos y espacios públicos que se subsana de forma parcial, con el paso del tiempo, a través de la reiterada demanda vecinal ${ }^{73}$. No es extraño, por tanto, que este escenario de partida condicione su evolución posterior y que en 2001, con una población de 7.156 residentes, el barrio registrara indicadores de vulnerabilidad socioeconómica (tasas de paro del 22,10\% y porcentaje de población sin estudios del $15,72 \%)^{74}$, por encima de la media municipal y fuera catalogado como barrio vulnerable. Su situación actual continúa siendo muy desfavorable y puede haberse acentuado como efecto de la crisis. De hecho, el último informe del IMAS (2014), recoge lo que puede calificarse como alarmante aumento del número de demandantes de ayuda, cifrado en 2012 en 3.319 personas, lo que representaba el $40 \%$ de la población residente en el barrio en aquella fecha.

En síntesis, se han seleccionado dos barrios surgidos en contextos históricos distintos, pero que comparten la condición de entornos desfavorecidos desde su origen. Desde el punto de vista de la dotación de espacios de relación vecinal, Santa Clara se caracteriza por la escasez de suelo destinado a uso público ${ }^{75}$. Para el estudio se han elegido las dos plazas de mayores dimensiones y que tienen una diferente génesis y localización. La ausencia de denominación oficial y, según parece, popular de estos espacios hace que se opte para su reconocimiento por la referencia a su desigual antigüedad: plaza antigua y plaza nueva de Santa Clara. La plaza antigua es anterior al proceso de reposición de viviendas y se trata de uno de los pocos lugares de relación tradicionales que se conserva el barrio. Se recuerda como el lugar habitual de juegos por las personas de mediana edad que residían en los bloques próximos. La segunda plaza seleccionada es, en cambio, posterior a las transformaciones en el entorno habitacional de finales del siglo XX. Supone la conversión en plaza de una zona deteriorada del barrio que, tras reiteradas demandas vecinales, se convierte en el mejor espacio público del conjunto del barrio. Aun así, presenta carencias dotacionales que, como se verá, son indicadas en los relatos de los residentes. Asimismo, los dos espacios difieren en su morfología. La primera es un recinto rectangular de dimensión media (cuadro 1), ubicado junto al colegio público del barrio, con vegetación arbustiva y arbórea que proporciona sombra a la mayoría del espacio. Al parecer no ha experimentado cambios significados desde su origen, según apuntan

73 Gestur, 2004, Díaz y García, 2014.

74 Ministerio de Fomento, 2011.

75 García, Armas y Díaz, 2013. 
en sus discursos los entrevistados. Sus dotaciones se limitan a media docena de bancos sin respaldo y papeleras y se puede apuntar que su limpieza y mantenimiento es reducido (figura 2). La plaza nueva es un lugar de dimensiones superiores que se organiza en tres niveles que conectan por rampas y escaleras. Se sitúa delante de un bloque de viviendas con acceso directo al espacio y su vegetación herbácea no aporta sombra. Cuenta con varios aparatos biosaludables, abundancia de bancos con respaldo, papeleras y un mural en el que aparecen los elementos más representativos del barrio. Su estado de mantenimiento y limpieza es mejor que el de la plaza antigua y, a diferencia de la anterior, en ella se señala la prohibición a la entrada de animales.

Cuadro 1. Características básicas de los espacios públicos seleccionados

\begin{tabular}{|c|c|c|c|c|}
\hline Barrio/espacio público & $\begin{array}{l}\text { Superficie } \\
\qquad\left(\mathrm{m}^{2}\right)\end{array}$ & Firme & Vegetación & Dotaciones \\
\hline Santa Clara/Plaza antigua & 1.288 & Loseta & Arbórea & $\begin{array}{r}\text { Bancos sin respaldo, } \\
\text { papeleras }\end{array}$ \\
\hline Santa Clara/Plaza nueva & 25.475 & Loseta & Herbácea & $\begin{array}{r}\text { Aparatos biosaludables, } \\
\text { bancos con respaldo y } \\
\text { papeleras }\end{array}$ \\
\hline Añaza/Plaza Nelson Mandela & 3.712 & $\begin{array}{l}\text { Tierra, grava } \\
\text { y asfalto }\end{array}$ & $\begin{array}{l}\text { Arbustiva y } \\
\text { arbórea }\end{array}$ & $\begin{array}{r}\text { Parque infantil, bancos } \\
\text { con respaldo y fuente } \\
\text { estropeada }\end{array}$ \\
\hline Añaza/Parque Hupalupa & 9.878 & $\begin{array}{l}\text { Tierra y lo- } \\
\text { seta }\end{array}$ & $\begin{array}{l}\text { Arbustiva y } \\
\text { arbórea }\end{array}$ & Bancos, papeleras \\
\hline
\end{tabular}

Fuente: Elaboración propia.

A diferencia de Santa Clara, el barrio de Añaza cuenta con un número elevado de metros cuadrados que se destinan a uso público, aunque su nivel de ejecución, dotación y mantenimiento resulta menos favorable que el análisis de su superficie76. Los espacios de relación seleccionados son una plaza de tamaño medio y un parque de mayores proporciones (cuadro 1). La primera se localiza en el núcleo inicial de vivienda social de la década de 1980, mientras que el parque se ubica en el extremo opuesto del barrio cuyo desarrollo se produce a partir de 1990. La plaza Nelson Mandela es un recinto cuadrado formado por dos sectores diferenciados: un tramo superior recorrido por una rampa con firme de tierra y grava y uno inferior con un área de juego infantil, una zona central que puede admitir diversos usos y un tercer perímetro con pequeños árboles, algunas palmeras y una fuente que no funciona. Los bancos de travesaños de madera y con respaldo constituyen una novedad en el barrio, junto con una buena iluminación. En conjunto es un lugar agradable que cuenta, sin duda, con la mejor dotación infantil de todo el barrio (figura 2). El parque Hermógenes Afonso de la Cruz - conocido popularmente como Hupalupa-, se sitúa enfrente del instituto y ocupa una superficie triangular adaptada a la topografía mediante paseos en zigzag. Destaca por ofrecer un diseño más cuidado

76 Díaz y García, 2014. 
que el resto de espacios públicos del barrio, aunque presenta carencias importantes para ser un buen lugar de encuentro: pavimento de tierra intransitable cuando llueve, bancos insuficientes, rotos y mal fijados a la superficie y déficit significativos en mantenimiento y limpieza. En síntesis, los cuatro espacios públicos seleccionados, aún siendo los que presentan las mejores condiciones en estos barrios, presentan también carencias importantes en cuanto a cantidad y calidad de dotaciones, así como un reducido mantenimiento y gestión, lo que contribuye a crear en ellos una imagen de abandono que no invita a su uso social.
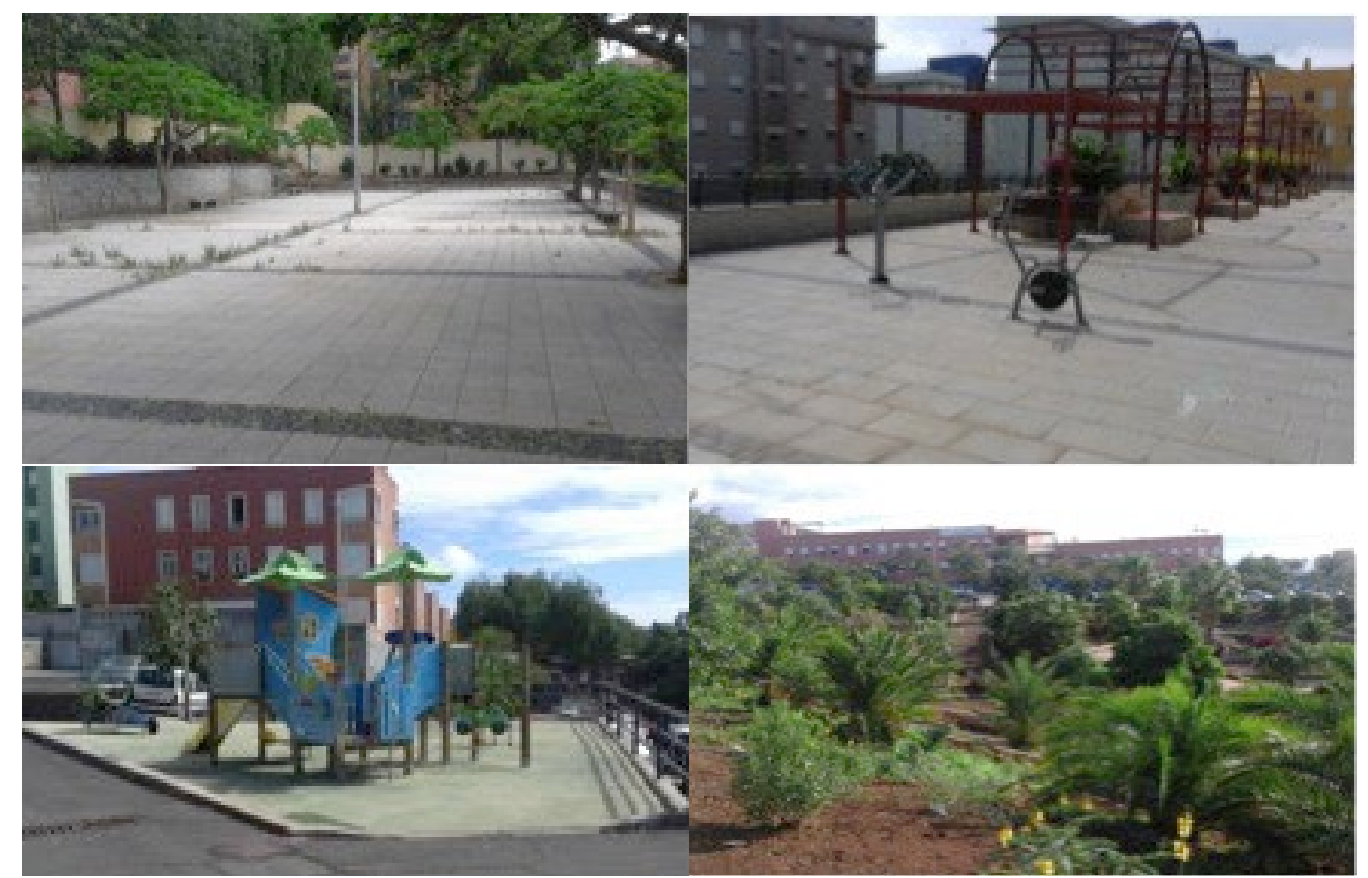

Figura 2. Fotografías de los espacios públicos estudiados. Superior izquierda, plaza antigua de Santa Clara; superior derecha, plaza nueva de Santa Clara; Inferior izquierda, plaza Nelson Mandela; inferior derecha, parque Hupalupa.

Fuente: El autor.

\section{Resultados. El espacio público: un elemento singular de la vulnera- bilidad urbana}

A continuación se exponen los resultados obtenidos del análisis de los espacios públicos, atendiendo a su uso, a las prácticas sociales que se desarrollan en ellos y a las experiencias y sentimientos de pertenencia hacia estos lugares de relación. Con ello, se espera obtener información acerca de su condición como espacio público en el sentido apuntado al inicio, así como de su contribución, en su situación actual, a la vulnerabilidad de estos barrios.

\section{Uso social de los espacios de relación: Momentos, presencias y ausencias}

El número de usuarios de los espacios públicos y su diversidad constituye habitualmente una expresión, en particular en espacios urbanos no centrales, de la mayor o 
menor vitalidad de la sociabilidad comunitaria ${ }^{77}$. Los espacios públicos compartidos por usuarios de distinto género, edad y otros rasgos identitarios pueden considerarse una manifestación de la importancia del lugar y de su centralidad en la vida cotidiana ${ }^{78}$. Los resultados obtenidos en los espacios públicos analizados muestran, en comparación con los ámbitos centrales de la ciudad ${ }^{79}$, un menor volumen de usuarios y un número más reducido de actividades o formas de uso. El análisis realizado permite explicar su reducida frecuentación y apunta algunas ideas que podrían optimizar su valor actual como ámbitos de encuentro.

Respecto a la afluencia de personas en función del turno y del día de la semana, es preciso comenzar señalando que no existe una pauta común, sino que cada espacio muestra ritmos propios ${ }^{80}$ (Cuadro 2). Así, se aprecia que mientras la plaza antigua de Santa Clara es frecuentada en similar proporción todos los días de la semana $-49,1 \%$ en días laborales y 50,9\% en festivos-, el espacio público de nueva creación de este barrio presenta una ocupación mayoritaria durante los días festivos $-8,8 \%$ en días laborales y $91,2 \%$ en festivos-. Aunque ambos espacios presentan un uso más intenso durante las tardes, en la plaza nueva esa tendencia es más evidente, lo que guarda relación con la diferente función que desempeña cada uno: el primero es el lugar de paseo habitual de la mascota y el segundo un ámbito que, aún sin tener dotación infantil, permite el ocio y esparcimiento de este grupo de edad.

Aquí a esta plaza [a la plaza antigua] creo que venimos cuatro a sacar el perro de vez en cuando. (Vecina, 54 años, residente en Santa Clara desde los 3 años).

Todas las tardes vengo aquí con la niña [a la plaza nueva], es el único espacio que tenemos y es así, grande, con espacio que los niños pueden jugar (Vecina, 39 años, residente en Santa Clara desde 2010).

Algo similar sucede en Añaza donde la plaza Nelson Mandela - el parque infantil por excelencia del barrio-, es más visitada fuera del horario escolar, esto es, en días festivos y turno de tarde $-37,3 \%$ en días laborables y $62,7 \%$ en festivos-.

Yo salgo de la ludoteca a las 8, ellos [los niños] salen a menos cuarto y yo salgo a las 8, cuando llego a mi casa todos los niños de la ludoteca, no digo todos pero sí un $60 \%$ está ahí en el parque [de la plaza Nelson Mandela]. (Vecina, 33 años, residente en Añaza desde 1989).

En cambio, la proximidad al Instituto de Enseñanza Secundaria de Añaza convierte al parque Hupalupa en un espacio más dinámico los días laborables $-68,1 \%$ en días laborables 31,9\% en festivos-, especialmente durante las tardes.

Es que está en muy malas condiciones, no hay mucho tránsito, a veces los chicos del instituto y para pasear el perro, eso ahí el único atractivo que tiene es para llevar el perro. (Vecino, 36 años, residente en Añaza desde 1991).

77 Saravi, 2004, Madanipour, 2010, Karsten, 2011.

78 Vaiou y Likogianni, 2008, Díaz-Cortés, 2009, Rodo-de-Zárate, 2011,

79 Calero, Delgado y Armas, 2014, Díaz et al., 2015.

80 Amin, 2006. 
Por tanto, además de la baja presencia de usuarios en los cuatro espacios públicos de estudio en cualquier momento del día y de la semana, se advierte la ausencia de un comportamiento prototípico en referencia a cuándo se produce un uso más intensivo, si bien existe una cierta pauta común que apunta que estos espacios muestran una mayor actividad durante las tardes y los días festivos. Las razones son diversas, pero sin duda el horario escolar y laboral juega un papel destacado en las dinámicas observadas en ambos barrios, tal como se desprende de las observaciones in situ y de las declaraciones de los vecinos ${ }^{81}$.

Cuadro 2. Porcentaje de usuarios según días laborables y festivos y turnos de mañana y tarde

\begin{tabular}{lcccccr} 
Espacio & Laboral & Festivo & Total & Mañanas & Tardes & Total \\
\hline Santa Clara-Plaza antigua & 49,1 & 50,9 & 100,0 & 39,6 & 60,4 & 100,0 \\
\hline Santa Clara-Plaza nueva & 8,8 & 91,2 & 100,0 & 14,7 & 85,3 & 100,0 \\
\hline Añaza-Plaza Nelson Mandela & 37,3 & 62,7 & 100,0 & 13,6 & 86,4 & 100,0 \\
\hline Añaza-Parque Hupalupa & 68,1 & 31,9 & 100,0 & 28,4 & 71,6 & 100,0 \\
\hline
\end{tabular}

El espacio público es uno de los ámbitos de la ciudad en el que se pueden producir procesos de exclusión, especialmente en aquellas áreas urbanas que presentan signos de vulnerabilidad social ${ }^{82}$. La ausencia de ciertos colectivos o su ubicación en sectores apartados de los grupos dominantes es un hecho habitual en el espacio público, donde se manifiesta la diferencia entre aquellos sujetos que se engloban en el "mainstream" social y los considerados "fuera de la norma"83. El análisis llevado a cabo permite discernir diferencias entre los usuarios de los lugares de relación atendiendo a sus rasgos identitarios y, en concreto, a las variables de género y edad (figura 3).

Es preciso resaltar como aspecto común a los espacios estudiados la ausencia de un uso similar por parte de hombres y mujeres de diferentes edades. En todos se aprecia el predominio de ciertos grupos, lo que responde a factores distintos y que apuntan a su limitado valor como ámbitos de esparcimiento para la colectividad. En este sentido, abundan las referencias que señalan que la diversidad de usuarios en el espacio público constituye un indicador de sus adecuadas condiciones como lugares para la sociabilidad y como ámbitos capaces de contribuir a la mejora de la calidad de vida urbana ${ }^{84}$.

81 El volumen de usuarios que resulta del promedio de las 8 observaciones realizadas durante 45 minutos en cada espacio es: Plaza antigua de Santa Clara, 7 usuarios; Plaza nueva de Santa Clara, 4 usuarios; Plaza Nelson Mandela, 7 usuarios; y parque Hupalupa, 9 usuarios.

82 Madanipour, 2010.

83 Iveson, 2003, Valentine, 2007.

84 Borja y Muxi, 2001, Mitchell, 2003, García-Ramón, Ortiz y Prats, 2014 


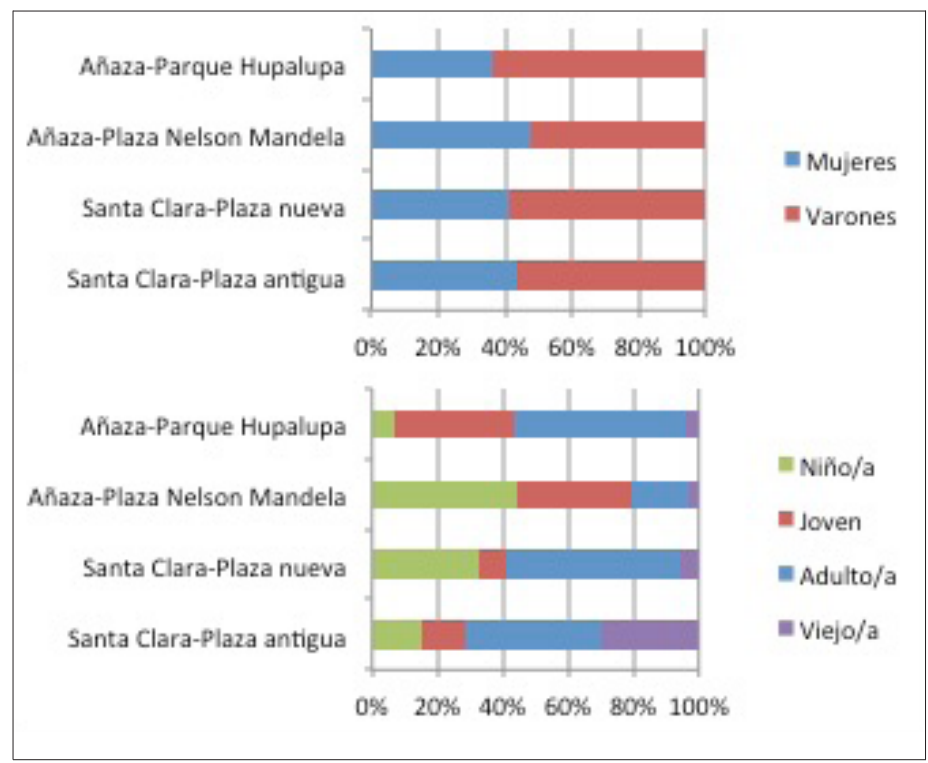

Figura 3: Porcentaje de usuarios por sexo y grupos de edad.

Fuente: Observación sistemática no participante. Elaboración propia.

Atendiendo a esta consideración, del análisis del espacio público de Santa Clara y Añaza se extrae una valoración desfavorable, al comprobar que son usados en mayor proporción por varones que mujeres y que los mayores se hayan prácticamente ausentes de estos lugares de relación. La plaza antigua de Santa Clara es usada por hombres y mujeres en parecida proporción, pero al introducir la edad se advierte un uso mayoritario por parte de adultos y una presencia reducida de niños y jóvenes. En la plaza nueva las diferencias de género son más significativas a favor de los varones, mientras la edad muestra presencia importante de adultos y casi no se identifican grupos de jóvenes y ancianos. El reducido uso y escaso significado social que para los jóvenes de Santa Clara poseen sus espacios próximos de relación, es paralelo al atractivo que en ellos genera la red de espacios públicos y centros comerciales del centro urbano, cuya visita constituye un modo habitual de pasar el tiempo libre ${ }^{85}$, un hecho que se reconoce al indicar "ah, esos van para abajo, a loquear para abajo, para Santa Cruz" (Vecina, 70 años, residente en Santa Clara desde 1979).

En Añaza, la plaza Nelson Mandela es usada en similar proporción por varones y féminas. Se trata de un espacio que adquiere una componente familiar al estar caracterizado por la presencia de menores que son cuidados en sus juegos por sus jóvenes progenitores. En este sentido, al tratar la problemática social del barrio, se advierte que la elevada proporción de madres a tempana edad es uno de los asuntos más recurridos,

Añaza tiene el problema de las chicas jóvenes que se quedan embarazadas muy jóvenes, no se dan cuenta que tienen una vida por delante y que después no están muy cualificadas para ser madres (Vecino, 36 años, residente en Añaza desde 1989).

85 Díaz et al., 2015. 
El parque Hupalupa parece un espacio con un uso masculinizado, una tendencia clara en los grupos adultos que se atenúa por la presencia en edades jóvenes de grupos de chicos y chicas en similar proporción.

No mucho, no hay mucho tránsito. Los chicos del instituto a veces cuando hacen cambios de horario veo que sí, que se ponen en grupos por la parte de arriba (Vecina, 47 años, residente en Añaza desde 2000).

En este caso, la mayor presencia masculina no parece obedecer a procesos de apropiación excluyente por parte de los hombres ${ }^{86}$, sino a otros factores como el tratarse de un espacio que no facilita el esparcimiento infantil. En relación con la edad, es destacable la ausencia de los grupos de edad mayores al ser un espacio con un pavimento y accesos que hacen complicado el tránsito a personas de movilidad reducida

Había una chica con dos perritos pequeños que tiene una silla de ruedas y ella llegó hasta la entrada y entonces los perritos entran y ella no, pero es que como tiene los accesos, si lo arreglaran (Vecina, 55 años, residente en Añaza desde 1994).

En síntesis, si evaluamos la calidad del espacio público atendiendo a su condición de lugares que favorezcan la estancia de múltiples y diversos usuarios, resulta difícil extraer una conclusión favorable en los barrios objeto de estudio, pues sus lugares abiertos de relación son escasamente usados por los residentes. De igual modo, la observación in situ y las declaraciones de los residentes señalan una mayor frecuentación por varones que por mujeres y, si atendemos a la distribución por edad, en todos ellos se evidencia el predominio de unos grupos en paralelo a las ausencias generalmente situadas en los extremos de la pirámide de edad. En este sentido, resulta sintomática la reducida presencia de ancianos en las plazas y parques analizados ${ }^{87}$, más aún al confirmar que este grupo de edad es, en ámbitos más centrales de esta ciudad, usuario habitual del espacio público por su disponibilidad de tiempo libre para el paseo, la conversación con otras personas o el entretenimiento de los nietos ${ }^{88}$. Lo cierto es que, en Santa Clara y Añaza, el diseño, mobiliario y la accesibilidad que la mayoría de estos espacios presentan no parecen responder a sus necesidades, lo que lleva a los mayores a buscar otros lugares de encuentro cerrados que puedan actuar como complementarios para el ocio y esparcimiento cuando el espacio público de su entorno de vida no ofrece unas mínimas condiciones que permitan la estancia.

Eso lo ha asumido todo la Avenida de los Príncipes. Hay varios locales que hacen actividades y ahí sí veo yo y también en el Complejo Polideportivo de Ofra, pero un barrio como tal y

86 Fenster, 2005, Vaiou y Lykogianni, 2006.

87 Santa Clara presenta una tasa de envejecimiento del $20,5 \%$, superior a la media municipal (17,5\%). Añaza, por su parte, con un 6,7\% de población vieja, es uno de los barrios con mayor juventud demográfica de la ciudad, si bien las secciones de más antigua formación empiezan a registrar tasas más elevadas.

88 Calero, Delgado y Armas, 2014. 
como se hacía antes ver gente sentada y compartiendo personas mayores, eso yo no lo he visto (Vecino, 31 años, natural de Santa Clara).

La gente que vino aquí éramos jóvenes, pero es que han pasado 25 años, somos mayores, tenemos los árboles más grandes pero es que no tenemos un banco, somos mayores y no tenemos un banco donde sentarnos, no tenemos donde ir a ver plantas, flores de temporada, aquí siempre es lo mismo (Vecina, 55 años, residente en Añaza desde 1994).

\section{Prácticas sociales y sentimientos de pertenencia: ¿Escasa calidad y mantenimien- to: reducidas actividades e identificación ciudadana?}

La combinación de las técnicas cualitativas empleadas en este estudio - observación sistemática no participante y entrevistas semiestructuradas - aporta resultados de interés para reconocer las formas de uso más habituales en los espacios públicos analizados y, también, para profundizar en la manera en que los usuarios desarrollan sus prácticas sociales, sobre su percepción de los lugares en los que las realizan y en la relevancia que tales espacios adquieren en su vida cotidiana. En este sentido, conviene tener presente los planteamientos que señalan que lo que hace público a un espacio no es su predestinado carácter público, sino el hecho de que cualquier grupo pueda hacer uso de él y a través de sus prácticas sociales, le den ese carácter de ámbito de colectividad creado por la sucesión de actividades cotidianas que le otorgan un significado social ${ }^{89}$.

Por ello, el análisis que se aporta pretende dar cuenta del carácter multifuncional o no de los lugares de relación trabajados y, al mismo tiempo, explorar las razones diversas que se hallan en el germen de las presencias, ausencias y comportamientos observados y de los sentimientos de identificación ciudadana. Los espacios abiertos de relación vecinal de los barrios de estudio presentan desventajas en los aspectos señalados, pues sus plazas y parques son usados de modo habitual por individuos con unos rasgos comunes de edad y género y en ellos existe una reducida variedad de prácticas sociales. En la figura 4 se aporta una síntesis de las prácticas sociales más habituales - descanso, paseo de la mascota, cuidado de niños, juegode los usuarios en los cuatro espacios públicos. En general, se aprecia el predominio de una o a lo sumo dos de estas modalidades, mientras las restantes tienen una presencia mínima o están ausentes. En la plaza antigua del barrio de Santa Clara el paseo a la mascota es la práctica más destacada, tanto en las mañanas como en las tardes seguida, a larga distancia, del juego infantil en horario vespertino (cuadro 3 ).

Atendiendo al discurso de los vecinos, es significativo comprobar que este espacio público era, en el periodo anterior a la reposición de los inmuebles, el núcleo principal de vida vecinal para los residentes en los bloques próximos. En cambio, a raíz de la transformación urbanística de este barrio, manteniendo la plaza el diseño y características anteriores, ha pasado a convertirse en un lugar de estancias breves.

Yo vivía aquí, o sea, yo salía y tenía el colegio aquí, que está al lado de la plaza, iba a mi casa, comía y venía a la plaza [plaza antigua de Santa Clara] (Vecino, 31 años, natural de Santa Clara).

89 Lefebvre, 1991, Mitchell, 2003. 
Esta plaza era una pasada. Aquí había muchos niños jugando, todos los niños jugando, unos jugaban al fútbol allí, otras jugaban aquí a las casitas, yo por ejemplo me asomaba porque yo vivía dónde está ese bloque y llamaba a mi hijo y me decía que, vale nada, era para saber dónde estabas... Ellos no salían de aquí de la placita y nosotros pasamos ahora por aquí y nos da tristeza (Vecina, 54 años, residente en Santa Clara desde los 3 años).

Las razones indicadas son diversas, pero sobresalen las referencias a cambios en los modos cotidianos de vida. Entre éstos, se apuntan modificaciones en el entretenimiento infantil - aumento del protagonismo de los videojuegos o actividades deportivas que implican el uso de otros espacios-. A un tiempo, se hace referencia a una necesidad de vigilancia por parte de los progenitores que no existía en décadas pasadas. Por último, es importante señalar que esta modificación de pautas de uso es considerada, por algunos vecinos, resultado de que la reposición de los inmuebles supusiera un cambio de localización en el barrio de los grupos de vecinos que residían en el mismo inmueble o cercanos y que compartían relaciones de vecindad y amistad.

Yo fui hace dos meses a ver la zona esa, porque claro yo añoro aquella parte y vine llorando... Ni un perro, ni una persona, ni nada, la plaza vacía, ni gente en la ventana, silencio. (Vecina, 62 años, residente en Santa Clara desde 1961).

Hombre, este es un espacio que antes usaban el bloque 27 y el bloque 26 de Santa Clara, esos bloques ya no existen, por tanto, esta plaza no está en uso... Esta plaza era donde todos nos poníamos de diferentes edades, desde los más pequeños hasta los grandes (Vecino, 31 años, natural de Santa Clara).

Cuadro 3. Porcentaje de usuarios según prácticas sociales en turnos de mañana y tarde en Santa Clara

\begin{tabular}{lrrrrrr} 
& \multicolumn{2}{c}{ Santa Clara-Plaza antigua } & \multicolumn{3}{c}{ Santa Clara-Plaza nueva } \\
\hline & Mañanas & Tardes & Total & Mañanas & Tardes & Total \\
\hline Descanso & 5,7 & 3,8 & 9,4 & 5,9 & 8,8 & 14,7 \\
\hline Paseo mascota & 24,5 & 35,8 & 60,4 & 5,9 & 2,9 & 8,8 \\
\hline Cuidar niños & 0,0 & 0,0 & 0,0 & 0,0 & 32,4 & 32,4 \\
\hline Juego & 0,0 & 11,3 & 11,3 & 0,0 & 32,4 & 32,4 \\
\hline Charlar & 5,7 & 9,4 & 15,1 & 2,9 & 2,9 & 5,9 \\
\hline Otros & 3,8 & 0,0 & 3,8 & 0,0 & 5,9 & 5,9 \\
\hline Total & 39,6 & 60,4 & 100,0 & 14,7 & 85,3 & 100,0
\end{tabular}

Fuente: Observación sistemática no participante. Elaboración propia.

A falta de un análisis más profundo sobre el particular, se aprecian evidencias de que la transformación del barrio, si bien dio lugar a una serie de mejoras necesarias en las condiciones materiales de las viviendas, tuvo algunos efectos no tan favorables como la ruptura del vínculo vecinal y el quebrantamiento de los sentimientos de pertenecía e identificación colectiva "todo Santa Clara lo botaron y con ello creo que botaron muchas cosas, también hay otras que no, pero a los que nos gustaba 
vivir donde vivíamos nos quitaron parte de nuestra vida" (Vecina, 54 años, residente en Añaza desde los 3 años).

Hace falta un parque infantil pero no lo hacen. Por lo visto los vecinos de las casas estas de la plaza no quieren, dicen que les molestan y hacen ruido, no entiendo, a mí los niños me dan vida pero ellos dicen que les molestan y que no quieren que hagan aquí un parque, pero de todos modos venimos a jugar aquí, esto por las tardes se llena de niños, siempre venimos los mismos (Vecina, 39 años, residente en Santa Clara desde 2010).

El tercer espacio, la plaza Nelson Mandela en Añaza, destaca por la importancia del juego infantil, especialmente concentrado en las tardes (Cuadro 4). Se trata de un lugar en el que las distintas prácticas observadas suponen el uso de diferentes sectores: por una parte, los niños con sus cuidadores - generalmente madres y padres jóvenes-, se sitúan en la zona del parque infantil y, por otro, la parte superior del espacio - constituida por rampas de tierra en deficitario estado- es usada de modo exclusivo por algunos chicos jóvenes para descansar o pasear la mascota. Las quejas más habituales enfatizan en la presencia de excrementos y la pendiente, que dificulta el tránsito a las personas mayores "Pues la verdad yo voy poco porque sinceramente no me gusta por las subiditas que tiene". (Vecina 70 años, residente en Añaza desde 1998). Más allá de su uso por parte de los citados colectivos, es una plaza carente de cualidades para otro tipo de usuarios.

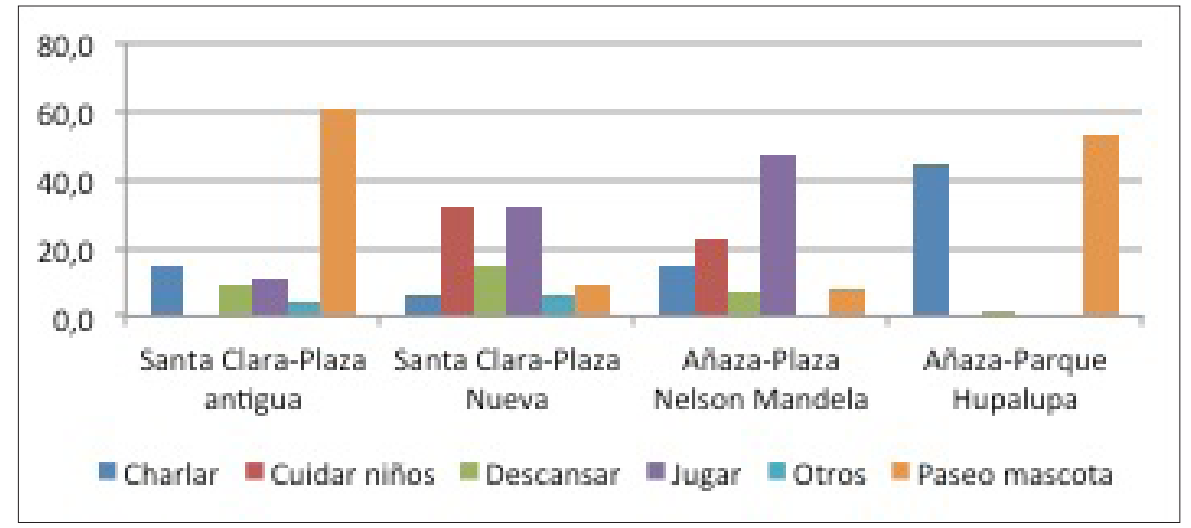

Figura 4: Porcentaje de usuarios según sus prácticas sociales.

Fuente: Observación no participante. Elaboración propia.

Espacios hay, bastantes, el problema es que no son atractivos para la ciudadanía. Bajo mi punto de vista la Nelson Mandela dejó de tener atractivo, si es verdad que van algunas madres a llevar a sus niños pero carece de asientos o hay uno o dos como mucho (Vecino, 36 años, residente en Añaza desde 1991).

Yo siempre la veo, es un sitio que veo y no digo, me voy a parar a sentarme un rato ahí (Vecino, 61 años, residente en Urbanización Acorán desde 1992) ${ }^{90}$.

En el último de los espacios públicos, el parque Hupalupa, se advierte menor diversidad de prácticas. El paseo de la mascota y la charla en grupos de amigos - 53,6\% y 44,9\% respectivamente- son las actividades observadas casi de modo exclusivo.

90 La Urbanización Acoran es una zona de carácter exclusivamente residencial, localizada al suroeste del barrio de Añaza, del que se encuentra separada por un barranco. Su crecimiento se inicia 
Ambas se desarrollan durante la mañana y la tarde, si bien la primera muestra un predominio en el turno de mañana, especialmente en las primeras horas del día, y la segunda se concentra en las tardes. Entre las razones más recurridas para explicar la escasa variedad de formas de vida colectiva en este espacio, sobresalen referencias a su nivel de deterioro y reducido mantenimiento que, por ejemplo, lo hace impracticable como ámbito de juego infantil, para hacer deporte o para el descanso de personas mayores

Cuadro 4. Porcentaje de usuarios según prácticas sociales en turnos de mañana y tarde en Añaza

\begin{tabular}{lrrrrrr}
\hline & \multicolumn{2}{c}{ Añaza-Plaza Nelson Mandela } & \multicolumn{3}{r}{ Añaza-Parque Hupalupa } \\
\hline & Mañanas & Tardes & Total & Mañanas & Tardes & Total \\
\hline Descanso & 3,4 & 3,4 & 6,8 & 0,0 & 1,4 & 1,4 \\
\hline Paseo mascota & 3,4 & 5,1 & 8,5 & 30,4 & 23,2 & 53,6 \\
\hline Cuidar niños & 1,7 & 20,3 & 22,0 & 0,0 & 0,0 & 0,0 \\
\hline Juego & 1,7 & 45,8 & 47,5 & 0,0 & 0,0 & 0,0 \\
\hline Charlar & 3,4 & 11,9 & 15,3 & 8,7 & 36,2 & 44,9 \\
\hline Otros & 0,0 & 0,0 & 0,0 & 0,0 & 0,0 & 0,0 \\
\hline Total & 13,6 & 86,4 & 100,0 & 39,1 & 60,9 & 100,0 \\
\hline
\end{tabular}

Fuente: Observación sistemática no participante. Elaboración propia.

Se ha quedado obsoleto porque es de tierra, eso es el punto neurálgico de los perros de abajo, de los vecinos que llevan a los perros ahí y claro, yo creo que eso se debería de transformar por una sencilla razón, tienes enfrente un centro estudiantil y muchos de ellos utilizan para comer ese espacio y deberíamos de dotarlo de otros atractivos para los jóvenes que para eso están ahí (Vecino, 37 años, residente en Añaza desde 1991).

Su escaso uso es al parecer un rasgo característico desde sus inicios, pues sus condiciones actuales y pasadas - dotaciones, mantenimiento, accesibilidad- actúan como límites nada fáciles de superar

No recuerdo que se usara tanto, no te creas que los parques de aquí se usan mucho, pero si me acuerdo los chicos del instituto salir y estar jugando allí en el parque. Incluso, recuerdo bajar al parque por las tardes después del instituto y jugar con compañeros que vivían en las viviendas que están cerca del parque. Pero siempre ha sido poco utilizado, estoy seguro (Vecino, 36 años, residente en Añaza desde 1989).

Por último, los entrevistados coinciden en la necesidad de una rehabilitación de este espacio en el que identifican claras posibilidades de conversión en un buen lugar de encuentro, más aún al conocer la situación de desventaja que presentan con respecto a parques urbanos similares situados en ámbitos más centrales de esta y otras ciudades.

a comienzos de la década de 1990 para clases medias y tiene la función propia de una ciudad dormitorio. 
El Hupalupa también está muy abandonado. La idea es que se recupere como algo para fomentar el deporte, no en plan Parque La Granja porque sería imposible, pero si a lo mejor a pequeña escala (Vecina, 33 años, residente en Añaza desde 1989).

Eso lo usa la gente por las tardes para dar un paseo, a sacar el perro, pero no es muy utilizado, ese parque es que necesita una rehabilitación a fondo, mayor iluminación, más cosas (Vecino, 65 años, residente en Añaza desde 1989).

Tanto la observación sistemática como el discurso vecinal aportan evidencias del escaso potencial como lugares de relación de los espacios públicos de los barrios de estudio, esto es, como ámbitos que puedan ser usados por usuarios diversos para el desarrollo de su vida cotidiana y para satisfacer necesidades de ocio y esparcimiento complementarias. El interés particular del estudio radica en la escasez de este tipo de análisis referidos a ciudades del sur europeo y, en particular, su inexistencia sobre las periferias desfavorecidas de las ciudades insulares canarias. Los resultados obtenidos coinciden con trabajos similares en el contexto anglosajón y español peninsular ${ }^{91}$, en la identificación del abandono y deterioro que muestran los espacios públicos en ámbitos con procesos de vulnerabilidad y exclusión social. Las fuerzas del mercado o el desarrollo de prácticas planificadoras que no benefician por igual a los distintos sectores de la ciudad, parecen ser una constante con implicaciones en el desigual acceso de la ciudadanía a su derecho al espacio público urbano ${ }^{92}$. En cambio, el caso de Santa Cruz de Tenerife difiere de las principales aportaciones consultadas en la no identificación en los lugares de relación de su periferia urbana, de un uso intensivo por parte de algunos grupos, que se apropian de estos espacios y, en ocasiones, excluyen o intimidan la presencia de otros colectivos ${ }^{93}$. En general, se reconoce una baja intensidad de uso y reducida variedad de prácticas motivadas, no por cuestiones relacionadas con la apropiación excluyente o con la seguridad, materia en que se han producido avances, sino por su reducida calidad y la necesidad de una serie de mejoras físicas de carácter básico.

Yo personalmente llevo toda mi vida aquí y he vuelto a mi casa a todas horas como persona joven que soy y nunca me han atracado, nunca me ha pasado nada (Vecina, 25 años, residente en Añaza desde su nacimiento).

Son espacios desangelados, o sea, no son atractivos para decir me voy a quedar ahí, voy a pasar un rato, me voy a encontrar con amigos (Vecino, 61 años, residente en urbanización Acorán desde 1992).

Desde ambos barrios se señala que no es solo una cuestión de mejoras dotacionales, sino que resulta precisa una dinamización social de estos lugares, que haga posible que los residentes les otorguen una posición destacada en su vida diaria y tenga repercusiones en el desarrollo de sentimientos de pertenencia e identificación colectiva.

91 Torres, 2005, Díaz-Cortés, 2009, Madanipour, 2010.

92 Mitchell, 2003

93 Saraví, 2004, Carrión, 2008. 
En este sentido, es evidente que un buen ámbito de relación no es aquel que cuenta con un mayor número de instalaciones, pero sí el que ofrece un conjunto de factores que facilitan un mayor sentido de lugar ${ }^{94}$.

No sé si es la palabra correcta, pero creo que hace falta como una dinamización comunitaria, es decir, que exista un trabajo en la calle, espacios puedes crear miles pero que no se haga una plaza para que venga la gente a pastar (Vecino, 33 años, natural de Santa Clara).

Hay muchos espacios para poder hacer muchas actividades diferentes, para los jóvenes, pues lo más probable que si hay muchas cosas que se podrán hacer, habrá gente especializada que sepa como poder realizarlo (Vecino, 36 años, residente en Añaza desde 1989).

Asimismo, el caso particular de Añaza difiere de realidades geográficas donde la cantidad limitada de espacio público crea una sensación de atrapamiento y en las que tales ámbitos constituyen un bien finito con la amenaza de invasión por parte de otras demandas ${ }^{95}$. El plan parcial que dio origen a este barrio dejó una proporción importante de suelo destinado a espacio libre público - sobre todo en sectores en que la topografía dificulta el desarrollo urbano-, de hecho, el discurso oficial indica que Añaza es uno de los barrios de la ciudad en que se ha destinado mayor superficie a espacios verdes y espacios públicos ${ }^{96}$. En cambio, el análisis de su dimensión cualitativa es el que aporta resultados desfavorables al igual que sucede en otros contextos

Pues yo creo que espacios sí que hay, un montón, además creo que en exceso también, igual que los servicios, lo que pasa es que están todos en mal estado, se han ido dejando abandonar... si te das un paseo por ellos verás que son casi intransitables, además de que está todo el mobiliario roto prácticamente, los bancos rotos, los columpios, los parques infantiles para los niños están ya fuera de reglamento, algunos los han quitado porque no han cumplido la normativa y no los han repuesto (Vecina, 33 años, residente en Añaza desde 1989).

De lo expuesto hasta aquí se puede concluir que los espacios públicos de estos barrios precisan intervenciones que mejoren su calidad, lo que motivaría una mayor frecuentación e influiría de modo favorable en el desarrollo de sentimientos colectivos de identificación y pertenencia. Con ese objetivo se podrían llevar a cabo intervenciones orientadas a la mejora de los aspectos formales que transformen los actuales espacios desprovistos de vegetación, accesos, zonas de transito interior, mobiliario y dotaciones básicas, mantenimiento y gestión, etc., en lugares agradables que puedan compartir usuarios con diferentes requerimientos. Asimismo, las actuaciones en su dimensión física, deberían ir acompañadas de una mayor atención a su papel como espacios de sociabilidad, que estimulen a la convivencia vecinal y, en definitiva, permitan al reforzamiento de los vínculos comunitarios ${ }^{97}$.

94 Ortiz, 2004.

95 Madanipour, 2010.

96 Gestur, 2004.

97 Segovia y Jordán, 2005. 


\section{Conclusiones}

La desigual dotación y calidad del espacio público en las diferentes áreas de la ciudad es uno de los testimonios de los procesos de segregación social y espacial existentes y, a la vez, un factor añadido de vulnerabilidad, que contribuye al reforzamiento de la precariedad y a la perpetuación de los barrios desfavorecidos. Entre las funciones más destacadas del espacio público figura su papel como lugar de sociabilidad y encuentro con capacidad, además, para la mejora de la vida cotidiana de las personas. La administración debe garantizar este derecho ciudadano a todos los residentes, para lo que se torna preciso su transformación, especialmente en periferias como las analizadas que acogen una proporción importante de población desfavorecida, no solamente por tener unos recursos económicos e indicadores educativos por debajo de la media municipal, sino por habitar en entornos con carencias.

Los barrios trabajados - Santa Clara y Añaza- comparten un carácter periférico. Se trata de entornos vulnerables desde su origen, que con la crisis económica iniciada en 2007 han visto reforzada su condición de ámbitos desfavorecidos. En estos contextos socioespaciales el espacio público si bien difiere en términos cuantitativos - en Añaza se destina a espacio público una cantidad importante de suelo, mientras en Santa Clara es limitada la superficie orientada a tal fin-converge en su escasa dotación y deficiente mantenimiento, al tiempo que presenta una baja intensidad de uso y reducida variedad de prácticas sociales. En términos generales, se advierte que el perfil dominante del usuario del espacio público en estos barrios es el de varón adulto y el paseo de la mascota se convierte en su práctica más frecuente en dos de los cuatro espacios estudiados. Este hecho es reconocido por un vecino al indicar "ahora hay un vinculo social muy extendido que es fundamentalmente tener un perro". En los restantes espacios el cuidado y el juego infantil es la actividad más destacada, pues a pesar de que el mantenimiento y dotaciones sean deficitarios son estos los lugares que posibilitan el esparcimiento al aire libre. En cambio, jóvenes y sobre todo mayores son colectivos ausentes en sus espacios públicos de proximidad, pues mientras los primeros parecen optar por pasar su tiempo de ocio en espacios con mayor dinamismo situados en el centro urbano, los mayores acuden a lugares de encuentro cerrados que funcionan como su única alternativa cuando las plazas y parques no les aportan unas condiciones mínimas para la estancia.

Se comprueba, por tanto, que la desatención hacia el espacio público de ámbitos urbanos desfavorecidos, identificada en otros contextos geográficos, se repite en este caso de estudio del sur de Europa. En cambio, las principales divergencias respecto a las aportaciones consultadas aparecen al analizar su uso y significado social. Mientras en otras áreas del planeta los lugares abiertos de relación muestran un uso intensivo y en ellos se producen procesos de apropiación excluyente por parte de determinados grupos que consideran el espacio como propio; en los barrios de estudio, el espacio público es escasamente frecuentado por los vecinos y posee un carácter indiferenciado, al carecer de atractivo y valor simbólico. 
Por todo lo dicho, la mejora de la calidad del espacio público en periferias desfavorecidas, constituye un requisito fundamental para reducir los múltiples procesos de vulnerabilidad socioespacial que padecen estos barrios, incrementar la calidad de vida urbana y lograr una ciudad menos segregada, donde no impere exclusivamente las políticas públicas de sesgo neoliberal que tienden a favorecer en este y otros aspectos a ámbitos sociales y espaciales mejor posicionados.

\section{Bibliografía}

ALGUACIL, Julio. Barrios desfavorecidos: diagnóstico de la situación española. Centros de investigación para la paz. En: VIDAL, Fernando. (Dir.) V Informe FUHEM de politicas sociales: la exclusión social y el estado del bienestar en España, Madrid: FUHEM, 2006, p. 155-168.

ALGUACIL, Julio, CAMACHO, Javier y HERNÁNDEZ-AJA, Agustín. La vulnerabilidad urbana en España. Identificación y evolución de los barrios vulnerables. EMPIRIA, Revista de Metodología de ciencias sociales, 2014, nº 27, p. 73-94

AMIN, Ash. Collective cultura and urban public space. City, 2006, vol. 12, no 1, p. 5-24.

ARMAS, Alejandro. Reestructuración urbana y producción de imagen: los espacios públicos en Santa Cruz de Tenerife. Tesis doctoral dirigida por Luz Marina García. Universidad de La Laguna, 2016.

ATTOH, Kafui. What kind of right is the right to the city? Progress in Human Geography, 2011 , vol. 35, no 5, p. 669-685.

AYUNTAMIENTO DE SANTA CRUZ DE TENERIFE. Construir la ciudad. Santa Cruz de Tenerife, 1983.

AYUNTAMIENTO DE SANTA CRUZ DE TENERIFE. Informe Añaza sobre la situación social del barrio. Departamento de Servicios Sociales, 1990.

BARRY, Brian. Social exclusión, social isolation and the distribution of income. En Hills, J., Le Grand y Piachaud, D. (Eds) Understanding social exclusión. London: Oxford University Press, 2010.

BENACH, Nuria. Espacios públicos: políticas urbanas y usos sociales. Biblio $3 W$. Revista Bibliográfica de geografía y ciencias sociales, 2015, vol. 20, no 11 17, p. 1-6.

BLANCO, Ismael y SUBIRATS, Joan. Políticas urbanas en España: dinámicas de transformación y retos ante la crisis. Geopolitica, 201 1, vol. 3, nº 1, p. 15-33.

BORJA, Jordi y CASTELLS, Manuel. Local y global. Management of cities in information age. HABITAT/London: Earthscan Publicationes Ltd., 1998.

BORJA, Jordi y MUXI, Zaida. Centros y espacios públicos como oportunidades. Perfiles latinoamericanos, (Ejemplar dedicado a: la nueva segregación urbana), 2001, p. 115-130.

BORJA, Jordi. Revolución urbana y derechos ciudadanos: claves para interpretar las contradicciones de la ciudad actual. Tesis doctoral dirigida por Horacio Capel. Universidad de Barcelona, 2012.

BRENNER, Neil y THEODORE, Nik. Spaces of neoliberalism. Urban restructuring in North America and Wertern Europe. Malden, MA: Blackwell Publishing, 2002. 
BRUQUETAS, María, MORENO, Fco. Javier y WALLISER, Andrés. La regeneración de barrios desfavorecidos. Documentos de trabajo (Laboratorio de alternativas), 2005 , $\mathrm{n}^{\mathrm{o}} 77, \mathrm{p} .1$.

BÜHLER, Elisabeth, KASPAR, Heidi y OSTERMANN, Frank. Soziale nachhaltilige Parkanlagen. Forchunsberich des Nationales Forschungsprogramms NFP 54 Nachtailige Siedlungs- und Infraestrukturentwicklung, Zürich, 2010. [En línea] $<$ http://www.vdf.ethz.ch/service/3309/3309_Sozial-nachhaltige-Parkanlagen_ OA.pdf $>$ [24 de junio de 2013]

CAPDEVILLE, Julieta, CECONATO, Diego y MANDRINI, María Rosa. Segregación urbana y mercantilización del territorio. Revista Iberoamerica de Urbanismo, 2013, no 9, p. 47-71.

CAQUIMBO, Sandra. La calidad del espacio público en la construcción del paisaje urbano. En busca de un hábitat equitativo. Revista INVI, 2008, vol. 22, nº 62, p. 75-97.

CARRIÓN, Fernando. Violencia urbana: un asunto de ciudad. EURE (Santiago), 2008, vol. 34, no 103, p. $111-130$.

DÍAZ-CORTÉS, Fabià. Espai public, vida quotidiana i identitat de barri a Tarrassa: la construccio material i social de Can Palet y Ca n'Anglada a través d'una geografía de la proximitat. Tesis doctoral dirigida por $\mathrm{M}^{\mathrm{a}}$ Dolors García-Ramón. Universitat Autònoma de Barcelona, 2009.

DÍAZ, M ${ }^{a}$ del Carmen, DELGADO, Carmen Rosa, CALERO, Carmen Gloria, GARCÍA, Luz Marina et al. Ciudad oscura, ciudad luminosa. Santa Cruz de Tenerife ( 1980 2000). Investigaciones Geográficas. Las Palmas de Gran Canaria, 2002, n 28, p. 33-51.

DÍAZ, Ma del Carmen y GARCÍA, Juan Samuel. El espacio público en áreas urbanas vulnerables: el caso de Añaza en Santa Cruz de Tenerife. Actas del XX Coloquio de Historia Canario-Americana, 2014, p. 118-129.

DÍAZ, Ma del Carmen, ARMAS, Alejandro, GARCÍA, Luz Marina y GARCÍA, Juan Samuel. Spaces of transition: young people's social practices in Santa Cruz de Tenerife (Canary Islands-Spain). Die Erde, 2015, vol. 146, nº 1, p. 63-73.

DÍAZ-ORUETA, Fernando y LOURÉS-SEAONE, Ma Luisa. Neoliberalismo, políticas urbanas y reconfiguración socio-espacial. Quid 16, 2014, nº 3, p. 7-16.

FENSTER, Tovi. The right to the gendered city. Diferent formations on belonging in everyday life. Journal of gender studies, 2005, vol. 14, nº 3, p. 217-231.

FUJITA, Kuniko (ed.). Cities and crisis. New critical urban theory. Londres: Sage, 2013.

GARCÍA, Luz Marina. ¿De cabañas a palacios? Vivienda y proceso de elitización en El Cabo-Los Llanos (Santa Cruz de Tenerife, Canarias). Scripta Nova. Revista Electrónica de Geografía y Ciencias Sociales. [En línea]. Barcelona: Universidad de Barcelona, 1 de agosto de 2003, vol. VII, no 146. <http://www.ub.edu/geocrit/sn/ sn-146(075).htm>. [26 de noviembre de 2015]. ISSN: 1138-9788. 
GARCÍA, Luz Marina. Santa Cruz de Tenerife, la formación de la ciudad marginal. Santa Cruz de Tenerife: Ediciones Idea, 2005.

GARCÍA, Luz Marina, SMITH, Neil y MEJÍAS, Miguel Ángel. Gentrification, displacement and tourism in Santa Cruz de Tenerife. Urban Geography, 2007, vol. 28, no 3, p. 276-298.

GARCÍA, Juan Samuel, ARMAS, Alejandro y DIAZ, Ma del Carmen. Análisis de las áreas urbanas vulnerables en Santa Cruz de Tenerife (Canarias): Aproximación desde los espacios públicos. XXIII Congreso de Geógrafos Españoles. Espacios insulares y de frontera. Una visión geográfica. Palma, Illes Balears, 2013, p. 567578.

GARCÍA-RAMÓN, Ma Dolors, ORTIZ, Anna y PRATS, María. Urban planning, gender and the use of public space in a peripherial neighbourhood of Barcelona. Cities. International Journal of Urban Policy and Planning, 2004 vol. 21 , no 3, p. 215-223.

GARCÍA-RAMÓN, Ma Dolors; ORTIZ-GUITART, Anna y PRATS, María (Coord). Espacios públicos, género y diversidad. Barcelona: Icaria Editorial, 2014.

GESTUR TENERIFE, S.A. Añaza, una idea hecha ciudad. Santa Cruz de Tenerife, Gestur, 2004.

GÓMEZ, Ma Victoria y ÁLVAREZ, Javier. La supervivencia de las ideas desreguladoras tras la crisis económica. Urban, 2013, nº 6, p. 39-51.

HACKWORTH, Jason. The neoliberal city. Governance, ideology and development in American urbanism. Ithaca, Cornell University Press, 2013.

HARVEY, David. Urbanismo y desigualdad social. Madrid, Siglo XXI, 1977.

HARVEY, David. Espacios del capital. Madrid, Akal, 2007.

HARVEY, David. Ciudades rebeldes. Del derecho a la ciudad a la revolución urbana. Ediciones akal, traducción de Juanmari Madariaga, 2013.

HILLS, John, LE GRAND, Julian y PIACHAUD, David. Understanding social exclusion. Oxford: Oxford University Press, 2002.

HODKINSON, Stuart. The new urban enclosures. City: Analysis of urban trends, culture, theory, policy, action, 2013, vol. 6, no 5, p. 500-518.

IMAS (2014). I Plan Municipal de Prevención Social y Desarrollo Comunitario. Ayuntamiento de Santa Cruz de Tenerife.

IVESON, Kurt. Justifying exclusion: The politics of public space and the dispute over Access to Mclvers ladies baths', Sidney. Gender, Place and Culture, 2003, vol. 10, $\mathrm{n}^{0} 3$, p. 215-228.

JANOSCHKA, Michael. Geografías urbanas en la era del neoliberalismo. Una conceptualización de la resistencia local a través de la participación y de la ciudadanía urbana. Investigaciones geográficas. Boletín del Instituto de Geografía, UNAN, 2011 , nº 76, p.118-132.

KARSTEN, Lia. Infancias diversas: redes sociales de los niños y las niñas en Ámsterdam. Documents d'anàlisi geográfica, 2011, vol. 57, nºl, p. 31-45.

KIDDER, Jeffrey. Parkour, the affective appropriation of urban space, and the Real/ Virtual Dialectic. City \& Community, 2012, vol. 11, no 3, p. 229-253. 
LAPARRA, Miguel. El primer impacto de la crisis en la cohesión social en España. Un análisis provisional a partir de las Encuestas Foessa 2007-2009. Madrid: Foessa y Cáritas, 2013.

LEFEBVRE, Henri. La vie quotidienne dans le monde moderne. Gallamard: París, 1968. LEFEBVRE, Henri. El derecho a la ciudad. Barcelona: Ediciones Península, 1969.

LEFEBVRE, Henri. The production of space. Oxford: Blackwell, 1991.

LEY, David y SAMUELS, Marwyn S. Humanistic Geography. Prospects and problems. London: Croom Helm, 1978.

LOW, Setha. On the plaza: The politics of public space and cultura. Austin: University of Texas Press, 2000.

MADANIPOUR, Ali. Marginal public space in European cities. In Madanipour A. (ed). Whose public space? International case studies in urban design and development. Oxford, 2010, p. 111-130.

MÄKINEN, Kirsi y TYRVÄINEN, Liisa. Teenage experiences of public green spaces in suburban Helsinki. Urban forestry an urban greening, 2008, vol. 7, no 4, p. 277-289

MARCUSE, Peter. What so new about divides cities. International Journal of Urban Regional Research, 1993, vol. 17, n³.

MARCUSE, Peter. Los derechos en las ciudades y el derecho a la ciudad. Gloobalhoy 23, 2010.

MÉNDEZ, Ricardo, ABAD, Luis D. y ECHAVES, Carlos. Atlas de la crisis. Impactos socioeconómicos y territorios vulnerables en España. Valencia: Tirant lo Blanch, 2015.

MINISTERIO DE FOMENTO. GOBIERNO DE ESPAÑA. Atlas de la vulnerabilidad urbana en España. Portal de suelo y políticas urbanas, 2011 . <http://siu.vivienda.es/ portal/index.php?option=com_content\&view=article\&id=103\&> [Consultado 29-12-2014].

MITCHELL, Don. The end of public space? People's park, definitions of public and democracy. Annals of the Association of American Geographers, 1995, vol. 85, nº 1 , p. 108-133.

MITCHELL, Don. The right to the city. Social justice and the fight for public space. Nueva York: Guilford Press, 2003.

MOULAERT, Frank, MARTINELLI, Flavia, SWYNGEDOW, Erik y GONZÁLEZ, Sara. Can neighbourhoods save the city? Nueva York: Routledge, 2010.

PERAHIA, Raquel. Las ciudades y su espacio público. IX Coloquio Internacional de Geocritica, 2007.

PERCY-SMITH, Janie (eds). Policy response to social exclusion, 2000, Londres, Open University Press.

PEREZ, Helena. La entrega de las 108 viviendas de San Pío pone fin al convenio de 1992. Diario de Avisos, 2000, p. 6.

ORTIZ, Anna. Génere, espais publics I construcció del sentir de pertinença a Barcelona. Elsbarris de Prosperitat, El Verdum i El Raval. Tesis doctoral dirigida por $\mathrm{M}^{\mathrm{a}}$ Dolors García Ramón. Universidad Autónoma de Barcelona, 2004. 
ORTIZ, Anna. Regeneración urbana, espacio público y sentido de lugar: Un caso de estudio en la ciudad de México. Provincia. [en línea]. 2006, nº 15, p. 41-63. <http://www.redalyc.org/pdf/555/55501503.pdf> [Consultado 22-03-2016].

OSTERMANN, Frank. Modeling, analyzing and visualizing human space appropiation. A case study on three urban public parks in Zurich, Switzerland. Tesis doctoral dirigida por Elizabeth Bühler. Universidad de Zürich, 2009.

RODÓ-DE-ZÁRATE, María. El jovent i els espais públics urbans des de la perspectiva de gènere: un estat de la qüestió des de la geografía. Documents d'anàlisi geográfica, 201 1, vol. 57, nº 1, p. 147-162.

SABATINI, Francisco. La segregación social del espacio en las ciudades de América Latina. Serie Azul, 2003, no 35, p. 59-70.

SABATÉ, Fernando, PERDOMO, Antonio C y AFONSO, Virginia. Las fuentes orales en los estudios de agroecología. El caso del agrosistema de Ycode (Tenerife). Santa Cruz de Tenerife: Centro de Conservación de la Biodiversidad Agrícola de Tenerife (CCBAT) Cabildo de Tenerife, 2008.

SARAVÍ, Gonzalo A. Segregación urbana y espacio público: los jóvenes en enclaves de pobreza estructural. Revista de la CEPAL, 2004, nº 83, p. 33-48.

SAVAGE, Mike, WARDE, Alan y WARD, Kevin Urban Sociology, Capitalism and Modernity. Basingstoke: macmillan, 2003.

SEGOVIA, Olga y JORDÁN, Rodrigo. Espacios públicos urbanos, pobreza y construcción social. Serie medio ambiente y desarrollo. División de Desarrollo Sostenible y Asentamientos Humanos, 2005.

SOCIEDAD DE DESARROLLO. Santa Cruz de Tenerife, situación socioeconómica y crisis, datos actualizados a mayo de 2013. Observatorio Socioeconómico Sociedad de Desarrollo Santa Cruz de Tenerife, 2013, p.97.

SUBIRATS, Joan, ALFAMA, Eva y OBRADORS, Anna. Ciudadanía e inclusión social frente a las inseguridades contemporáneas. La significación del empleo. Documentos de trabajo (Fundación Carolina), 2009, nº 32, p. 133-142.

TALESNIK, Daniel y GUTIÉRREZ, Alejandro (eds). Transformaciones de frentes de agua: la forma urbana como producto estándar. Revista EURE, 2002, vol. XXVIII, $n^{\circ} 84$, p. 21-31.

TAYLOR, Steven J. y BOGDAN, Robert. Introducción a los métodos cualitativos de investigación. La búsqueda de significados. Barcelona: Paidós 1996.

TORRES, Francisco José. El análisis territorial aplicado al estudio de zonas urbanas marginadas, el caso de Polígono Sur en Sevilla. Grupo de investigación Estructura y sistemas territoriales. Universidad de Sevilla, Consejería para la Igualdad y Bienestar social, 2005.

TORRES, Francisco José y GARCÍA, Luz Marina. Metodologías para el análisis de la desigualdad urbana y la exclusión social. Aplicación al caso de la ciudad de Sevilla y sus barrios. Eria, 201 1, no 84-85, p. 103-108.

TUAN, Yi-Fu. Space and place: The perspective of experience. Minneapolis: University of Minesota, 1977. 
VAIOU, Dina y LIKOGIANNI Rouli. Women, Neighbourhoods and Everyday Life. Urban Studies, 2006, vol. 43, n 4, p. 731 - 743.

VALENTINE, Gill. Theorizing and researching intersectionality: a challenge for feminist geography. The professional geographer, 2007, vol. 59, $\mathrm{n}^{\mathrm{o}}$ 1, p. 10-21

VILAGRASA, Joan. Los debates sobre pobreza urbana y segregación social en Estados Unidos. Scripta Nova. Revista Electrónica de Geografía y Ciencias Sociales. [En línea]. Barcelona: Universidad de Barcelona, 15 de noviembre de 2000, n 76. <http://www.ub.edu/geocrit/sn-76.htm> [Consultado 29-12-2012]. ISSN 1138 9788

VIVES MIRÓ, Sonia y RULLÁN, Onofre. La vivienda en el tránsito de la reproducción ampliada del capital a la acumulación por desposesión en España. XII Coloquio y Trabajos de Campo del Grupo de Geografía Urbana (AGE), 2014, p. 1-16.

WEHRAHN, Rainer y DOMINIC, Haubrich. Vecindades contestadas: seguridad y construcción de espacios urbanos en Sao Paulo. Les Ataliers du SAL, 2014, nº5, p. 57-71.

(c) Copyright: Juan Samuel García Hernandez, 2017

(c) Copyright Scripta Nova, 2017.

Ficha bibliográfica:

GARCÍA-HERNANDEZ, Juan Manuel. El espacio público en periferias desfavorecidas: Añaza y Santa Clara paradigmas de vulnerabilidad socioespacial en Santa Cruz de Tenerife. Scripta Nova. Revista Electrónica de Geografía y Ciencias Sociales. [En línea]. Barcelona: Universidad de Barcelona, 15 de junio de 2017, vol. XXI, nº 569. ISSN: 1138-9788. 